\title{
Arsenic Trioxide Synergistically Promotes the Antileukaemic Activity of Venetoclax by Downregulating Mcl-1 in Acute Myeloid Leukaemia Cells
}

Hyunsoo Cho

Yonsei University College of Medicine

Ji Eun Jang

Yonsei University College of Medicine

Ju-In Eom

Yonsei University College of Medicine Hoi-Kyung Jeung

Yonsei University College of Medicine Haerim Chung

Yonsei University College of Medicine Jin Seok Kim

Yonsei University College of Medicine

June-Won Cheong

Yonsei University College of Medicine

Yoo Hong Min ( $\sim$ MINBRMMD@yuhs.ac)

Yonsei University College of Medicine

\section{Research}

Keywords: Acute myeloid leukaemia, venetoclax, arsenic trioxide, apoptosis

Posted Date: December 28th, 2020

DOI: https://doi.org/10.21203/rs.3.rs-130872/v1

License: (c) (i) This work is licensed under a Creative Commons Attribution 4.0 International License. Read Full License 


\section{Abstract}

\section{Background}

The evasion of apoptosis through dysregulated Bcl-2 family members is a hallmark of leukaemia stem cells (LSCs) in acute myeloid leukaemia (AML). Therefore, targeting Bcl-2 with venetoclax has been suggested as an attractive strategy for inducing apoptosis in AML LSCs. However, the selective inhibition of $\mathrm{Bcl}-2$ in $\mathrm{AML}$ often leads to upregulation of $\mathrm{Mcl}-1$, another dominant anti-apoptotic $\mathrm{Bcl}-2$ family protein conferring venetoclax resistance.

Methods

We assessed the combined effect of venetoclax and arsenic trioxide (ATO) on leukaemic cell viability, apoptosis, combination index, and cell cycle in the human LSC-like KG1 and KG1a cells. The synergistic effect of venetoclax and ATO on apoptosis was also examined in primary CD34 ${ }^{+}$and $\mathrm{CD} 34^{+} \mathrm{CD} 38^{-} \mathrm{LSCs}$ from the bone marrow (BM) of AML patients, and compared with those from healthy donors.

Results

Venetoclax efficiently impaired cell viability and dose-dependently promoted apoptosis when combined with ATO; their synergism was aptly represented by the combination index. The combination of venetoclax and ATO impaired cell cycle progression by restricting cells within the sub-G1 phase and facilitating caspase-dependent apoptotic cell death associated with the loss of mitochondrial membrane potential, while sparing healthy BM haematopoietic stem cells. Mechanistically, ATO mitigated venetoclax-induced upregulation of Mcl-1 by the inhibition of AKT and ERK, along with activation of GSK$3 \beta$. This led to the Mcl-1 destabilisation, triggering Noxa and Bim to facilitate apoptosis and the consequent activation of the apoptosis executioner protein Bak. Moreover, the combination promoted phosphorylation of ATM, Chk2, p38, and H2AX, indicating an active DNA damage response.

\section{Conclusions}

Our findings demonstrate the synergistic, preferential antileukaemic effects of venetoclax and ATO on LSCs, providing a rationale for preclinical and clinical trials by combining these agents already being used in clinical practice to treat acute leukaemia.

\section{Background}

Acute myeloid leukaemia (AML) is a heterogeneous haematological malignancy involving haematopoietic stem cells (HSCs) and progenitor cells $(1,2)$. Although a substantial proportion of AML patients achieve a complete remission with intensive cytotoxic chemotherapy, most patients succumb to disease relapse (1-3). AML relapse is considered to originate from leukaemia stem cells (LSCs), which are metabolically quiescent, capable of self-renewal, and responsible for chemotherapy resistance $(4,5)$. 
Therefore, more effective therapeutic strategies targeting LSCs are required to improve the cure rate in AML.

$\mathrm{Bcl}-2$ protein is frequently overexpressed in AML LSCs (6); this overexpression is associated with chemotherapy resistance, culminating in dismal clinical outcomes (7). In this regard, development and clinical trials of $\mathrm{Bcl}-2$ inhibitors have been conducted during recent years (8). Venetoclax (ABT-199) is a $\mathrm{BH} 3$ mimetic, which selectively inhibits Bcl-2 and stabilises proapoptotic proteins (9). It was shown that venetoclax can induce LSC cytotoxicity while largely sparing normal HSCs (10). However, the biological and clinical actions of venetoclax employed as a single-agent have produced unsatisfactory results in AML (8). Thus, the combination approach was developed, leading to approval for the use of venetoclax in combination with DNA methyltransferase inhibitors or low-dose cytarabine for elderly patients with newly diagnosed AML and those patients deemed unfit for conventional cytotoxic chemotherapy (11-15). However, up to one-third of patients do not respond to these regimens $(16,17)$. Besides, the majority of AML patients who achieve remission after receiving these combination therapies ultimately relapse, with a median duration of response of only about a year $(16,17)$. Hence, there is an urgent requirement to elucidate the molecular mechanism underlying venetoclax resistance and develop novel combination strategies to target and overcome this resistance.

Mcl-1 is a critical anti-apoptotic protein that regulates cell survival in AML (18-20). Mcl-1 upregulation coincides with episodes of relapse in chemotherapy-treated AML, emphasising the role of Mcl-1 in the development of drug resistance $(21,22)$. Furthermore, emerging evidence suggests the upregulation of Mcl-1 protein as one of the mechanisms underlying acquired resistance to venetoclax treatment in $\mathrm{AML}$ (20-22). Therefore, selective inhibitors of Mcl-1 are currently being investigated in preclinical and clinical studies on haematological malignancies, including AML (20). However, the clinical development programme for a safe and selective $\mathrm{Mcl}-1$ inhibitor has proven challenging so far. The large size, high lipophilicity, poor pharmacokinetic profile, limited cell membrane permeability, and shallow binding groove on Mcl-1 are the major hurdles impeding the development of Mcl-1 inhibitors (23). Therefore, it is important to identify clinically available agents that interfere with $\mathrm{Mcl}-1$ to augment the therapeutic efficacy of venetoclax in AML.

Arsenic trioxide (ATO) is a potent agent against acute promyelocytic leukaemia (APL) (24) and imparts a significant survival benefit in patients with relapsed APL (25). Furthermore, recently acquired evidence favours the use of ATO with all-trans retinoic acid (ATRA) over anthracycline-based therapy as a first-line treatment option in newly diagnosed APL patients (26). The toxicity profile of the ATO and ATRA combination appeared to be mild, with minimal myelosuppression and manageable adverse effects (26). APL cell death by ATO is triggered by the generation of intracellular reactive oxygen species and induction of DNA damage response (27). Indeed, ATO activates the intrinsic apoptotic pathway by lowering the mitochondrial membrane potential; additionally, ATO-induced apoptosis is associated with the downregulation of Bcl-2 and activation of proapoptotic executioner protein Bax (28). Notably, ATO downregulates Mcl-1 expression in APL cells (29), although the underlying mechanism is not fully elucidated. 
In the present study, we investigated whether the combination of venetoclax and ATO efficiently promotes apoptosis in AML LSC-like cells. Using LSC-like cell lines, as well as CD $34^{+}$CD $38^{-}$primary AML cells and bone marrow (BM) cells from healthy donors, we demonstrated that the combination of venetoclax and ATO synergistically and selectively exhibits anti-AML activity in vitro, simultaneously sparing normal HSCs. We demonstrated that venetoclax-induced Mcl-1 upregulation is mitigated by ATO in AML LSC-like cells and revealed that downregulation of increased Mcl-1 levels is associated with the activation of GSK$3 \beta$. Our findings support a strategy for developing an effective and safe non-chemotherapeutic-based AML treatment regimen using a successful combination of venetoclax and ATO.

\section{Methods}

\section{Cell lines and patient samples}

This study was carried out in accordance with the Declaration of Helsinki and approved by the Institutional Review Board of Severance Hospital (Yonsei University College of Medicine, Seoul, Republic of Korea; 4-2010-0669). KG1 and KG1a human leukaemia cell lines were obtained from the American Type Culture Collection (Manassas, VA, USA). KG1 cells were cultured in Roswell Park Memorial Institute1640 medium (Gibco, Thermo Fisher Scientific, Waltham, MA, USA), and KG1a cells were cultured in Iscove's modified Dulbecco's medium (Gibco). All media were supplemented with $10 \%$ foetal bovine serum, $100 \mathrm{U} / \mathrm{mL}$ penicillin, and $100 \mu \mathrm{g} / \mathrm{mL}$ streptomycin (Gibco) at $37^{\circ} \mathrm{C}$ in a humidified environment under $5 \% \mathrm{CO}_{2}$. Primary samples were obtained from the BM aspirates of AML patients at diagnosis $(n=4)$ and healthy donors who donated their BM aspirates for allogeneic haematopoietic stem cell transplantation (HSCT) $(n=4)$. To minimise the confounding effects specific to cytogenetic and/or molecular abnormalities, we utilised primary AML blasts only from cytogenetically normal AML patients without recurrent mutations. The clinical characteristics of AML patients at diagnosis are summarised in Supplementary Table 1. BM mononuclear cells (BMMCs) were isolated by Ficoll-Hypaque (GE Healthcare, Chicago, IL, USA) density gradient centrifugation. The patient cohort was registered at ClinicalTrials.gov (NCT02344966), and all patients and healthy donors provided written informed consent.

\section{Cell culture and treatment}

A stock solution of venetoclax (Selleckchem, Houston, TX, USA) was prepared in dimethyl sulfoxide (DMSO), and serial dilutions were prepared in culture medium prior to each experiment. The final DMSO concentration was less than $0.2 \%(\mathrm{v} / \mathrm{v})$ in all experiments. ATO $\left(\mathrm{As}_{2} \mathrm{O}_{3}\right.$, Sigma-Aldrich, St. Louis, MO, USA) was dissolved in $1.65 \mathrm{M} \mathrm{NaOH}$ at $5 \times 10^{-2} \mathrm{M}$ to form a stock solution. The maximum concentration of $\mathrm{NaOH}$ in culture did not influence the growth of these cell lines. Logarithmically growing cells $\left(1 \times 10^{5}\right.$ cells $/ \mathrm{mL}$ ) were exposed to different concentrations of venetoclax in the presence/absence of various concentrations of ATO. The pan-caspase inhibitor z-VAD-fmk (R\&D Systems, Minneapolis, MN, USA) was added to the cells $2 \mathrm{~h}$ prior to venetoclax and ATO treatment. 


\section{Reagents and antibodies}

Rabbit polyclonal antibodies against caspase-9, caspase-3, poly(ADP-ribose) polymerase (PARP), phospho-p38, Mcl-1, phospho-Mcl-1 (T163), Bim, Bak, Bax, phospho-GSK-3区 (S9), GSK-3区, phospho-AKT (S437), AKT, phospho-ERK (T202/Y204), phospho-ATR (S428), phospho-Chk1 (S317), phospho-Chk2 (T68), and p53 were purchased from Cell Signaling Technology (Danvers, MA, USA). The rabbit polyclonal antibody against $\mathrm{Bcl}-\mathrm{xL}$ and mouse anti-Bcl-2 and anti-Noxa monoclonal antibodies were obtained from Santa Cruz Biotechnology (Dallas, TX, USA). The rabbit polyclonal antibody against phospho-Mcl-1 (S159) was obtained from BioVision (Milpitas, CA, USA). The rabbit polyclonal antibody against phosphoATM (S1981) and mouse anti-phospho-H2AX (S139) monoclonal antibody were obtained from Abcam (Cambridge, UK). Horseradish peroxidase (HRP)-conjugated goat anti-rabbit IgG and HRP-conjugated goat anti-mouse IgG were from Cell Signaling Technology. The mouse anti-a-Tubulin monoclonal antibody was obtained from Merck Millipore (Burlington MA, USA).

\section{Mcl-1 overexpression by transient transfection}

The generation of Mcl-1 plasmid pcDNA3.1-Mcl-1 was described previously (30). Briefly, a suspension of $2 \times 10^{6} \mathrm{KG} 1$ a cells was transfected with $1 \mu \mathrm{g}$ of pcDNA3.1 or pcDNA3.1-Mcl-1 using programme V-01 of the Amaxa Nucleofector device (Lonza Cologne $\mathrm{GmbH}$, Cologne, Germany) according to the manufacturer's instructions. Immediately after electroporation, the cells were resuspended in complete medium and incubated at $37^{\circ} \mathrm{C}$ in a humidified atmosphere containing $5 \% \mathrm{CO}_{2}$ for $48 \mathrm{~h}$.

\section{Assessment of cell viability}

Cells were seeded in 96-well plates $\left(1 \times 10^{5} \mathrm{cell} / \mathrm{mL}\right)$ and incubated overnight before treatment. After 48 $\mathrm{h}$ of treatment with the indicated concentrations of venetoclax in the presence/absence of ATO, $10 \mu \mathrm{L}$ of the Cell Counting Kit-8 solution (Dojindo Molecular Technologies, Rockville, MD, USA) was added to each well. After incubation for $4 \mathrm{~h}$, the absorbance at $450 \mathrm{~nm}$ was measured with a microplate reader (VersaMax, Molecular Devices, San Jose, CA, USA).

\section{Apoptosis assay}

Apoptosis evaluation was performed by an Annexin V binding assay using LSR Fortessa flow cytometer (BD Biosciences, Franklin Lakes, NJ, USA). Cells were treated with various concentrations of venetoclax with or without ATO for $48 \mathrm{~h}$ and resuspended in Annexin $\mathrm{V}$ binding buffer. They were then incubated with Annexin V-FITC (BD Biosciences) and propidium iodide (PI) or 7-AAD (Beckman Coulter, Brea, CA, USA) for 15 min before flow cytometry analysis. To examine the apoptosis in the $\mathrm{CD} 34^{+} \mathrm{CD} 38^{-}$cell fraction, cells were stained with anti-CD34-APC (BD Biosciences), anti-CD38-PE (BD Biosciences), and 7-AAD (Beckman Coulter) for $30 \mathrm{~min}$. The labelled cells were subsequently resuspended in Annexin $\mathrm{V}$ binding buffer and incubated with Annexin V-FITC (BD Pharmingen) for 15 min before flow cytometry analysis. Data were analysed using the FACSuite software (BD Biosciences). 


\section{Cell cycle analysis}

Following each treatment cycle, cells were harvested, washed twice with PBS, and fixed in $70 \%$ ethanol at $-20{ }^{\circ} \mathrm{C}$ for $16 \mathrm{~h}$. The fixed cells were washed twice with PBS and stained with PI for 15 min at $37^{\circ} \mathrm{C}$. Analysis of cells with sub-G1, G0/G1, S, and G2/M DNA content was performed using 10,000 cells on an LSR Fortessa flow cytometer (BD Biosciences). Data were analysed using the FACSuite software (BD Biosciences).

\section{Combination index}

The combination effect was evaluated via quantitative analysis of dose-effect relationships based on the Chou-Talalay method as described previously (31). A combination index $(\mathrm{Cl})$ value was calculated using the CalcuSyn software (Biosoft, San Francisco, CA, USA); $\mathrm{Cl}<1$ was considered synergistic, $\mathrm{Cl}=1$ was considered additive, and $\mathrm{Cl}>1$ was considered antagonistic.

\section{Analysis of mitochondrial membrane potential}

The mitochondrial membrane potential (MMP) was monitored using $\mathrm{DiOC}_{6}$, as described previously (32). For each condition, $1 \times 10^{6}$ cells were incubated with $1 \mathrm{~mL}$ of DePsipher solution (Trevigen, Gaithersburg, MD, USA), which uses a cationic dye (5,5'6,6'-tetrachloro-1,1',3,3'tetraethylbenzimidazolylcarbocyanine iodide). After incubation for $20 \mathrm{~min}$ at $37^{\circ} \mathrm{C}$ in a $5 \% \mathrm{CO}_{2}$ incubator, cells were washed with $1 \mathrm{~mL}$ of prewarmed 1X Reaction Buffer with Stabiliser Solution and subsequently analysed using an LSR Fortessa flow cytometer (488 nm argon laser) and the FACSuite software (BD Biosciences).

\section{Western blot analysis}

For protein extraction, cells were lysed with a radioimmunoprecipitation (RIPA) assay buffer (Thermo Fisher Scientific) supplemented with protease and phosphatase inhibitors (Roche, Basel, Switzerland). Cell lysates were centrifuged for $10 \mathrm{~min}$ at $4{ }^{\circ} \mathrm{C}$ and $13,000 \mathrm{rpm}$. Protein concentrations of the supernatants were quantitated using the detergent-insensitive Pierce BCA protein assay kit (Thermo Fisher Scientific). Lamni buffer was added to total protein lysates, and samples were denatured at $95^{\circ} \mathrm{C}$ for $5 \mathrm{~min}$. Aliquots of each protein lysate $(10 \mu \mathrm{g})$ were subjected to SDS-PAGE. After electrophoresis, proteins were transferred to nitrocellulose membranes and blocked for $30 \mathrm{~min}$ with $5 \%$ bovine serum albumin in $0.1 \%$ Tween 20 in TBS (TBST). Primary antibodies were incubated overnight at $4{ }^{\circ} \mathrm{C}$. After washing with TBST, membranes were incubated with the secondary peroxidase-coupled antibody for $1 \mathrm{~h}$ at room temperature and washed with TBST. The blots were visualised using enhanced chemiluminescence substrates (GE Healthcare). a-Tubulin was used as a loading control.

\section{Statistical analyses}

All values are presented as mean \pm standard deviation (s.d.). The statistical significance of differences between two groups was determined by the two-tailed unpaired $t$-test, one-way analysis of variance (ANOVA) followed by Tukey's honest significant difference test with ranks for multiple-group comparison, 
or two-way ANOVA with Bonferroni post-hoc analysis. Statistical analyses were performed using GraphPad Prism 8 (GraphPad Software, San Diego, CA, USA). Statistical significance was considered at $P$ $<0.05$.

\section{Results}

\section{The venetoclax and ATO combination synergistically promotes apoptosis in AML LSC-like cells}

To assess the combined antileukaemic effects of the venetoclax and ATO in AML LSC-like cells, we used the KG1 cell line, which is characterised by the high surface expression of CD34 but lacking CD38 $\left(\mathrm{CD} 34^{+} \mathrm{CD} 38^{-}\right)$. The KG1a cell line, with similar phenotypic characteristics, was also included in the present study. We first treated these two cell lines with various concentrations of venetoclax $(0-1,000$ $\mu \mathrm{M})$ in the presence/absence of ATO $(3 \mu \mathrm{M})$. After incubation for $48 \mathrm{~h}$, cell viability, apoptosis, and cellcycle distribution were examined using the respective methods described in Methods. As shown in Fig. $1 a, b$, the decrease in the level of cell viability was minimal to modest with the single-agent treatment of increasing concentrations of venetoclax in KG1 and KG1a cells. However, venetoclax substantially impaired the viability of these cells in a dose-dependent manner, when treated in combination with ATO (Fig. 1a, b).

We then measured the proportion of apoptotic cells using Annexin $\mathrm{V}$ and PI co-staining and flow cytometry analysis in these cells following treatment with increasing concentrations of venetoclax $(0-$ $1,000 \mu \mathrm{M})$ in the presence/absence of ATO $(3 \mu \mathrm{M})$. A consistent trend was noted, involving a significant rise in apoptosis rate with the combination of venetoclax and ATO in KG1 and KG1a cells; however, only a minimal to a modest degree of apoptosis was observed following venetoclax treatment alone (Fig. 1c, d). A noteworthy observation was that the cell death-enhancing effects of ATO were evident even with the lower doses of venetoclax (Fig. 1c, d). The combination effect generated by venetoclax and ATO on apoptosis was further examined by quantitative analysis of the dose-effect relationships based on the Chou-Talalay method (31). As shown in Fig. 1e, f, there was a synergistic effect on apoptosis generated by the interaction between venetoclax and ATO; this was further indicated by $\mathrm{Cl}$ values less than 1 in both KG1 and KG1a cells.

Further analysis of cell cycle distribution revealed that the proportion of cells in the sub- $\mathrm{G}_{1}$ phase was significantly increased after the venetoclax and ATO combination treatment compared with either agent alone, indicating that the disrupted cell cycle caused by the combination treatment may be linked to the induction of apoptosis (Fig. 2a, b).

The venetoclax and ATO combination preferentially induces apoptosis in primary CD $34^{+} \mathrm{AML}$ cells while sparing HSCs from healthy donors

To further examine whether ATO effectively promotes the venetoclax-induced apoptosis in primary AML LSC-like cells, we harvested diagnostic BMMCs from AML patients without any cytogenetic abnormalities. The clinical characteristics of the AML patients are summarised in Supplementary Table 1. 
BMMCs from AML patients were treated with $100 \mathrm{nM}$ of venetoclax in the presence/absence of $3 \mu \mathrm{M}$ of ATO. After $48 \mathrm{~h}$ of incubation, the fraction of apoptotic cells was measured among the blast gate, $\mathrm{CD} 34^{+}$ blasts, and $\mathrm{CD} 34^{+} \mathrm{CD} 38^{-}$cells using Annexin $\mathrm{V}$ and 7-AAD staining and flow cytometry analysis. Representative flow cytometric plots of gated $\mathrm{CD} 34^{+} \mathrm{CD} 38^{-}$primary AML cells after the single or combination treatment with venetoclax and ATO are shown in Fig. $\mathbf{3 a .}$

With venetoclax treatment alone, the frequencies of Annexin $\mathrm{V}^{+} 7-\mathrm{AAD}^{+}$apoptotic cells in the mononuclear cell blast gate, $\mathrm{CD} 34^{+}$blasts, and $\mathrm{CD} 34^{+} \mathrm{CD} 38^{-}$blast population were $33.93 \pm 9.13 \%, 49.98 \pm 9.31 \%$, and $58.51 \pm 6.42$, respectively (Fig. 3b). After ATO treatment alone, the apoptotic cell fraction was $11.54 \pm 7.51 \%, 7.91 \pm 6.79 \%$, and $19.1 \pm 12.3 \%$ in the mononuclear cell blast gate, CD $34^{+}$blast, and CD34 ${ }^{+}$CD38 blast population, respectively (Fig. 3b). However, with the combination treatment of venetoclax and ATO, the apoptotic fraction was significantly increased to $68.00 \pm 5.66 \%$ in the mononuclear cell blast gate ( $P=0.0007$ vs venetoclax alone; $P<0.0001$ vs ATO alone) (Fig. $3 b)$. The differences in the level of apoptosis remained significant when analyses were performed for gated CD34 ${ }^{+}$ cells and CD34 ${ }^{+}$CD 38 ${ }^{-}$LSC-like cells (for CD34 ${ }^{+}$cells, $P=0.0031$ vs venetoclax and $P<0.0001$ vs ATO; for CD34 ${ }^{+}$CD38 blasts, $P=0.0002$ vs venetoclax and $P<0.0001$ vs ATO) (Fig. 3b).

Interestingly, as depicted in the representative flow cytometric plots of gated CD $34^{+} \mathrm{CD} 38^{-}$cells after the single or combination treatment with venetoclax and ATO in the BMMCs of healthy donors (Fig. $3 \mathrm{c}$ ), the combined effect of these agents on apoptosis was minimal in CD $34^{+} \mathrm{CD} 38^{-}$cells as well as in the gated blasts, CD $34^{+}$cells of healthy BMMCs (Fig. 3d). These findings implied that the combination of venetoclax and ATO promotes induction of apoptosis preferentially in bulk AML cells and LSC-like cells while sparing HSCs.

\section{The venetoclax and ATO combination potentially activates the caspasedependent mitochondrial apoptotic pathway}

We next evaluated the changes in caspase cleavage and MMP to unravel the mechanism of cell death involved in the combination of venetoclax and ATO in LSC-like cells. Compared with a single treatment, the combination of venetoclax and ATO resulted in an increase in the levels of cleaved caspase-9, cleaved caspase-3, and cleaved PARP (Fig. 4a).

To further investigate the cell death mechanism potentially triggered by the combination of venetoclax and ATO, MMP was analysed by flow cytometry using the $\mathrm{DiOC}_{6}$ probe. The venetoclax and ATO combination robustly induced a higher degree of MMP depolarisation compared with the extent of depolarisation induced by a single treatment with either agent in both KG1 and KG1a cells (Fig. 4b). Next, apoptotic status was analysed after the preincubation of these cells with pan-caspase inhibitor z-VADfmk $(20 \mu \mathrm{M})$ for $2 \mathrm{~h}$. As shown in Fig 4c, d, z-VAD-fmk preincubation significantly alleviated apoptosis induction by combination treatment with venetoclax and ATO in both KG1 and KG1a cells. Collectively, these findings indicated that the synergistic increase in the rate of apoptosis by the venetoclax and ATO 
combination is, at least in part, attributable to the activation of the caspase-dependent mitochondrial apoptotic pathway.

\section{Mcl-1 protein is downregulated by adding ATO to venetoclax treatment in KG1 and KG1a cells}

To elucidate the molecular mechanisms involved in the synergistic increase in apoptosis level with the combination of venetoclax and ATO, we next examined the effects of this combination on the Bcl-2 family members, which are critical regulators of apoptosis (7). There were no apparent changes in the protein level of $\mathrm{Bcl}-2$ following treatment with venetoclax in the presence/absence of ATO for $48 \mathrm{~h}$ in KG1 and KG1a cells (Fig. 5a). However, cleaved Bcl-2 was generated after treatment with ATO alone or in combination with venetoclax in KG1a cells, which was not observed in KG1 cells (Fig. 5a), suggesting the contextual differences between these cells with respect to the molecular alterations involving the cellular apoptosis machinery.

Next, we evaluated the changes in the Mcl-1 protein level. There was a noticeable elevation in the Mcl-1 protein level with venetoclax single treatment in both KG1 and KG1a cells (Fig. 5a). However, when these cells were treated with the combination of venetoclax and ATO, Mcl-1 protein levels were substantially downregulated in both these cell types (Fig. 5a). Remarkably, alleviation of the venetoclax-induced upregulation of Mcl-1 by ATO addition was conspicuous in KG1a cells (Fig. 5a).

To further elucidate the mechanism of Mcl-1 protein downregulation, we investigated the levels of $\mathrm{Mcl}-1$ phosphorylation at Ser ${ }^{159}\left(\mathrm{p}-\mathrm{Mcl}-1 \mathrm{Ser}^{159}\right)$ as well as at $\mathrm{Thr}^{163}$ residue (p-Mcl-1 Thr $\left.{ }^{163}\right)$. In parallel with the downregulation of Mcl-1 protein, the level of $\mathrm{p}-\mathrm{Mcl}-1$ Ser $^{159}$ was increased, whereas the level of $\mathrm{p}-\mathrm{Mcl}-$ $1 \mathrm{Thr}^{163}$ was decreased following the combination treatment of venetoclax and ATO in both KG1 and KG1a cells (Fig. 5a). However, the change in the protein expression level of another anti-apoptotic member, Bcl-xL, was minimal after the combination treatment or either agent alone (Fig. 5a).

Notably, the protein level of Noxa, which is antagonised by Mcl-1 (33), was elevated after venetoclax and ATO combination treatment in both KG1 and KG1a cells (Fig. 5b). Likewise, the increase in the proapoptotic protein level of Bim, which forms a complex with Mcl-1 (7), was highest when these cells were treated with the combination of venetoclax and ATO (Fig. $\mathbf{5 b}$ ). The protein level of Bak, which is a core regulator of mitochondrial outer membrane permeabilisation and apoptosis that is normally sequestered by Mcl-1 (7), was strongly induced upon combination treatment, especially in KG1a cells, while to a lesser extent with ATO single treatment (Fig. 5b). The change in the protein level of another proapoptotic effector Bax was minimal, implying that Bax may not be a major contributor to enhanced cell death with the venetoclax and ATO combination in these cells (Fig. 5b). Taken together, these findings indicated that Noxa and Bim may be untethered from Mcl-1-mediated binding through downregulation of Mcl-1, leading to the increased induction of apoptosis associated with Bak activation.

\section{The venetoclax and ATO combination activates GSK-3 $\beta$ in KG1 and KG1a cells}


Since GSK-3 $\beta$ activation promotes p-Mcl-1 Ser ${ }^{159}$ leading to proteasomal degradation of Mcl-1 protein (7), we evaluated GSK-3 $\beta$ activity by measuring the level of GSK-3 $\beta$ phosphorylation at Ser $^{9}$ (p-GSK-3 $\beta$ $\left.\operatorname{Ser}^{9}\right)$. Although the change in the total protein level of GSK-3 $\beta$ was minimal, the level of $p-G S K-3 \beta$ Ser ${ }^{9}$ was notably decreased after treatment with ATO. This was mediated by enhanced GSK-3 $\beta$ activity induced by adding ATO to venetoclax treatment in KG1 and KG1a cells (Fig. 5c). The phosphorylated form of AKT (Ser ${ }^{473}$ ) was diminished without significant changes in the level of total AKT by the combination treatment in both these cell types (Fig. 5c). The level of phosphorylated ERK $\left(\mathrm{Thr}^{202} / \mathrm{Tyr}^{204}\right)$, which phosphorylates Mcl-1 at the $\mathrm{Thr}^{163}$ residue ( $\mathrm{p}$ - Mcl-1 $\mathrm{Thr}^{163}$ ) and stabilises $\mathrm{Mcl}-1$, was also reduced in KG1 and KG1a cells in response to treatment with the combination of venetoclax and ATO (Fig. $\mathbf{5 c}$ ). These results signified that venetoclax-induced Mcl- 1 upregulation is mitigated by ATO via GSK-3 $\beta$ activation-mediated increase in the level of $\mathrm{p}-\mathrm{Mcl}-1 \mathrm{Ser}^{159}$ and decrease in the level of $\mathrm{p}-\mathrm{Mcl}-1 \mathrm{Thr}^{163}$. This may subsequently lead to the proteasomal degradation and destabilsation of Mcl-1 protein.

\section{Ectopic Mcl-1 overexpression alleviates the venetoclax and ATO combination-induced apoptosis}

To further elucidate the role of Mcl-1 downregulation in the venetoclax and ATO combination-induced synergistic cell death, Mcl-1 overexpression was ectopically induced in KG1 a cells (Fig. 6a), as described in Methods. Briefly, KG1a cells were transfected with pcDNA3.1 control or pcDNA3.1-Mcl-1 vector, and the level of apoptosis was examined with the Annexin V and PI staining after the single or combined treatment with venetoclax and ATO (Fig. 6b). The proportion of apoptotic cells was significantly diminished after the combination treatment in KG1a cells upon Mcl-1 overexpression ( $52.80 \pm 6.59 \%)$, compared with the combination treatment in control KG1a cells without Mcl-1 overexpression $(72.50 \pm 5.47 \%, P=0.0286$ ) (Fig. 6b,c). These findings indicate that downregulation of Mcl-1 is critically involved in the synergistic increase in the level of apoptosis in AML LSC-like cells treated with a combination of venetoclax and ATO.

\section{Venetoclax and ATO combination triggers robust DNA damage response}

The findings above led us to explore the changes in the level of proteins involved in the DNA damage response after venetoclax and ATO treatment alone or in combination in KG1 and KG1a cells. As shown in Fig. 7, the combination of venetoclax and ATO robustly increased the levels of p-ATM $\left(\operatorname{Ser}^{1981}\right)$ and p$\mathrm{H} 2 \mathrm{AX}\left(\mathrm{Ser}^{139}\right.$ ) compared with the single treatment of either agent alone. In parallel, Chk2 phosphorylation at $\mathrm{Thr}^{68}$ residue was markedly augmented with the combination treatment (Fig. 7). Phosphorylation of p38 mitogen-activated protein kinase (MAPK) was also augmented with the combined treatment of venetoclax and ATO compared with the treatment of either agent alone (Fig. 7), signifying the robust induction of apoptosis by the combination treatment in these cells. However, compared with the phosphorylation of ATM and Chk2, the phosphorylation of ATR $\left(\mathrm{Ser}^{428}\right)$ and Chk1 $\left(\mathrm{Ser}^{317}\right)$ were modest following the combination treatment (Fig. 7). Changes in p53 protein expression levels were not apparent in both KG1 and KG1a cells (Fig. 7). Taken together, these findings implied that p53-independent DNA 
damage response, especially the p-ATM $\left(\mathrm{Ser}^{1981}\right)$ and p-Chk2 $\left(\mathrm{Thr}^{68}\right)$ pathway, is associated with enhanced induction of apoptosis by the combination of venetoclax and ATO.

\section{Discussion}

AML LSCs express elevated levels of Bcl-2, which mediates disease initiation and progression, as well as the development of chemotherapeutic resistance (16). In this regard, Bcl-2 has emerged as a promising therapeutic target specific for LSCs. Furthermore, the selective inhibition of $\mathrm{Bcl}-2$ with venetoclax has proven to be an encouraging treatment option for AML. However, another dominant anti-apoptotic Bcl-2 family member, Mcl-1, is upregulated upon selective Bcl-2 inhibition, leading to the resistance of LSCs to venetoclax $(34,35)$.

In the present study, we demonstrated that a combination of venetoclax and ATO synergistically promotes apoptosis in LSC-like leukaemia cells and induces apoptosis preferentially in primary LSCs from AML patients, concomitantly sparing HSCs from healthy donors. We further revealed that ATO mitigates venetoclax-induced upregulation of Mcl-1. The synergistic effects of this venetoclax and ATO combination are mediated by attenuated AKT and ERK with GSK-3 $\beta$ activation, consequently triggering Mcl-1 destabilisation and degradation, via the activation of caspase-dependent apoptotic cell death and untethering of Noxa and Bim from Mcl-1, and Bak activation, associated with a strong DNA damage response (Fig. 8).

Our data reinforce the prevailing concept of Mcl-1 as an important resistance factor to venetoclax and confirm prior studies delineating Mcl-1 as a mediator of the differential responsiveness to ATO between APL and non-APL cells (29). It was proposed that ATO distinctly downregulates Mcl-1 via GSK-3 $\beta$ activation in APL cells; however, this was not the case in non-APL cells, where the additional modulation of the Mcl-1 level was necessary to sensitise non-APL cells to ATO-induced apoptosis (29). Supporting this notion, we revealed that ATO activates GSK-3 $\beta$ in KG1 and KG1a cells when combined with venetoclax, which was associated with attenuated AKT and enhanced phosphorylation of Mcl-1 at Ser ${ }^{159}$, subsequently leading to $\mathrm{Mcl}-1$ degradation. We also showed that the combination reduces $\mathrm{p}$-ERK levels and diminishes $\mathrm{Mcl}-1$ phosphorylation at $\mathrm{Thr}^{163}$, which is required for Mcl-1 stabilisation (36). These results jointly indicated that ATO-induced downregulation of the increased Mcl-1 level in venetoclaxtreated KG1 and KG1a cells could occur via similar mechanisms to those employed in ATO-treated APL cells. We can also postulate that the venetoclax and ATO combination-induced decrease in the Mcl-1 protein level can be attributed, at least in part, to post-translational modification.

Venetoclax treatment combined with the direct inhibition of $\mathrm{Mcl}-1$ by a lentiviral $\mathrm{BH}$-expressing vector is efficacious in overcoming venetoclax resistance in xenograft models of AML (37). Moreover, the addition of the selective Mcl-1 inhibitor S63845 (38, 39), AMG 176, or AM-8621 (40) enhances the sensitivity to venetoclax in $A M L$ cell lines as well as in primary AML cells. Indeed, these synergistic effects are also observed in AML progenitor cells (31). However, similar to other anti-apoptotic proteins of the Bcl-2 family, Mcl-1 plays a vital role in the survival of various cells of normal tissues, including cardiac and hepatic 
cells $(41,42)$, pluripotent stem cells $(43)$, and neurons (44). The development of selective Mcl- 1 inhibitors is seriously hampered by safety concerns and technical drawbacks in targeting Mcl-1 (23). Therefore, these challenges require extensive validation of observed results before direct $\mathrm{Mcl}-1$ inhibitors become easily accessible and applicable in routine clinical practice (20).

A range of compounds indirectly causes a decline in the cellular level of Mcl-1 and its key signalling molecules. XP01-selective inhibitor selinexor $(45,46)$, autophagy inhibitor spautin-1 $(47)$, tyrosine kinase inhibitor sorafenib $(48,49)$, survivin inhibitor YM1 $55(50)$, and CDK9 inhibitors $(51,52)$ are the representative compounds. Furthermore, MAPK signalling regulation by $p 53$ activation (53), inhibitors of Nedd8-activating enzyme (54), as well as MEK (55), MDM2 (56), glutaminase (57), and pan-RAF (55) inhibitors have also been shown to reduce the level of Mcl-1. Although preclinical studies have demonstrated these agents' efficacy, only a few of them are being investigated in clinical trials. It is anticipated that there would be a prolonged period preceding the application of safe and tolerable modulators of Mcl-1. Hence, it is extremely crucial to identify readily available and clinically applicable agents that inhibit Mcl-1 to improve the therapeutic efficacy of venetoclax. In this regard, the venetoclax and ATO combination may serve as a feasible and safe option for treating AML patients, as they possess a relatively optimal tolerability profile and non-overlapping harmful effects (58).

It has been recently recognised that the combination of venetoclax and ATO induces apoptosis in NPM1mutated OCl-AML3 cells, which constitute the cell line inherently resistant to venetoclax (59). OCI-AML3 cells express high levels of Mcl-1, which has been shown to be further upregulated upon treatment with venetoclax (53). However, the NPM1 mutation in OCI-AML3 cells confers sensitivity to ATO even in the absence of venetoclax (60), and the changes in the level of Mcl-1 underlying the proposed synergism have not yet been demonstrated. Our data support the synergistic antileukaemic effects of venetoclax and ATO and provide mechanistic insights that the synergism between venetoclax and ATO is mediated via ATO-mediated Mcl-1 downregulation.

We demonstrated that the combination of venetoclax and ATO spares HSCs from healthy donors while concomitantly promoting apoptosis in LSC-like cells. Homeostasis of healthy HSCs is regulated by oxidative phosphorylation (OXPHOS)-driven regeneration and glycolysis-mediated quiescence (61). This balance is dysregulated in AML LSCs, as LSCs preferentially depend on mitochondrial OXPHOS to a greater degree than on glycolysis (5). Considering that ATO activates quiescent HSCs and LSCs (62), the simultaneous inhibition of increased mitochondrial OXPHOS by venetoclax and unleashing LSC quiescence by ATO could have cooperatively sensitised LSCs to the combination treatment while sparing healthy HSCs. Indeed, no appreciable therapeutic effects of ATO as a single-agent in non-APL AML cells have been demonstrated to date $(37,63,64)$, where we also observed the modest induction of apoptosis by ATO treatment alone. Given that ATO is relatively safe and tolerable in the current clinical settings (65), our data may provide the rationale for future preclinical and clinical trials for prolonged infusion of ATO in combination with venetoclax, which may generate an opportunity to capture a larger proportion of leukaemic cells, including LSCs, which asynchronously enter the S phase (62). 
We highlighted the synergism between venetoclax and ATO in mutant p53-expressing KG1 and KG1a cell lines. There were minimal changes in p53 protein expression when these cells were treated with either venetoclax and ATO alone or in combination. Although p53 activation and Bcl-2 inhibition have been shown to reciprocally overcome resistance to each other in primary AML cells, at least in part, through the negative regulation of $\mathrm{Mcl}-1$ by p53 (53), our results showed that the benefits of the venetoclax and ATO combination treatment in promoting apoptosis are efficacious irrespective of the p53 status. Therefore, our study may provide an opportunity for improving outcomes in patients harbouring p53-mutated AML, which is marked by an extremely poor prognosis $(2,66)$. Moreover, our proposed concept may not be limited to AML. Other haematological malignancies expressing high levels of both Bcl-2 and Mcl-1, such as multiple myeloma (67), may also benefit from the venetoclax and ATO combination, which needs to be validated in future research.

\section{Conclusions}

In summary, our study elucidates the synergism between venetoclax and ATO in promoting LSC apoptosis by inhibiting AKT and ERK, leading to GSK-3 $\beta$ activation and Mcl-1 destabilisation, which will support future preclinical and clinical trials evaluating the suitability of this combination for treating AML. This finding may lead to exciting prospects for a chemotherapy-free approach, especially for AML patients who are vulnerable and not strong enough to undergo high-intensity chemotherapy.

\section{Abbreviations}

AML: acute myeloid leukaemia; APL: acute promyelocytic leukaemia; ATRA: all-trans retinoic acid; BM: bone marrow; BMMC: BM mononuclear cell; DMSO: dimethyl sulfoxide; ATO: arsenic trioxide; HSC: haematopoietic stem cell; HSCT: haematopoietic stem cell transplantation; LSC: leukaemic stem cell; MAPK: mitogen-activated protein kinase; MMP: mitochondrial membrane potential; OXPHOS: oxidative phosphorylation; PARP: poly(ADP-ribose) polymerase; PI: propidium iodide; RIPA: radioimmunoprecipitation; ROS: reactive oxygen species.

\section{Declarations}

\section{Ethics approval and consent to participate}

This study was carried out in accordance with the Declaration of Helsinki and approved by the Institutional Review Board of Severance Hospital (Yonsei University College of Medicine, Seoul, Republic of Korea; 4-2010-0669). The patient cohort was registered at ClinicalTrials.gov (NCT02344966), and all patients and healthy donors provided written informed consent.

\section{Consent for publication}

Not applicable. 


\section{Competing interests}

The authors declare no potential conflicts of interest.

\section{Availability of data and materials}

Source data and materials in this study are available from the corresponding author upon reasonable request.

\section{Funding}

This research was supported in part by SK Plasma (2018). The funders had no role in the study design, data collection and analysis, decision to publish, or manuscript preparation.

\section{Authors' contributions}

$\mathrm{HC}$ performed the experiments, interpreted the data, and wrote the manuscript; JEJ designed the study, interpreted the data, and codirected the project; JIE and HKJ performed the experiments and interpreted the data; HaC, JSK, and JWC provided clinical samples and interpreted the data; YHM conceived and designed the study, interpreted the data, wrote the manuscript, and directed the project.

\section{Acknowledgements}

We greatly appreciate Dr. Sung-Dae Cho (Seoul National University) for sharing the pcDNA3.1-Mcl-1 plasmid.

\section{References}

1. Khwaja A, Bjorkholm M, Gale RE, Levine RL, Jordan CT, Ehninger G, et al. Acute myeloid leukaemia. Nat Rev Dis Primers. 2016;2:16010.

2. Dohner H, Estey E, Grimwade D, Amadori S, Appelbaum FR, Buchner T, et al. Diagnosis and management of AML in adults: $2017 \mathrm{ELN}$ recommendations from an international expert panel. Blood. 2017;129(4):424-47.

3. Yang X, Wang J. Precision therapy for acute myeloid leukemia. J Hematol Oncol. 2018;11(1):3.

4. Pollyea DA, Jordan CT. Therapeutic targeting of acute myeloid leukemia stem cells. Blood. 2017;129(12):1627-35.

5. Yamashita M, Dellorusso PV, Olson OC, Passegue E. Dysregulated haematopoietic stem cell behaviour in myeloid leukaemogenesis. Nat Rev Cancer. 2020;20(7):365-82.

6. Lagadinou ED, Sach A, Callahan K, Rossi RM, Neering SJ, Minhajuddin M, et al. BCL-2 inhibition targets oxidative phosphorylation and selectively eradicates quiescent human leukemia stem cells. Cell Stem Cell. 2013;12(3):329-41. 
7. Perini GF, Ribeiro GN, Pinto Neto JV, Campos LT, Hamerschlak N. BCL-2 as therapeutic target for hematological malignancies. J Hematol Oncol. 2018;11(1):65.

8. Konopleva M, Letai A. BCL-2 inhibition in AML: an unexpected bonus? Blood. 2018;132(10):1007-12.

9. Pan R, Hogdal LJ, Benito JM, Bucci D, Han L, Borthakur G, et al. Selective BCL-2 inhibition by ABT-199 causes on-target cell death in acute myeloid leukemia. Cancer Discov. 2014;4(3):362-75.

10. Pollyea DA, Stevens BM, Jones CL, Winters A, Pei S, Minhajuddin M, et al. Venetoclax with azacitidine disrupts energy metabolism and targets leukemia stem cells in patients with acute myeloid leukemia. Nat Med. 2018;24(12):1859-66.

11. DiNardo CD, Pratz KW, Letai A, Jonas BA, Wei AH, Thirman M, et al. Safety and preliminary efficacy of venetoclax with decitabine or azacitidine in elderly patients with previously untreated acute myeloid leukaemia: a non-randomised, open-label, phase 1b study. Lancet Oncol. 2018;19(2):216-28.

12. DiNardo CD, Rausch CR, Benton C, Kadia T, Jain N, Pemmaraju N, et al. Clinical experience with the BCL2-inhibitor venetoclax in combination therapy for relapsed and refractory acute myeloid leukemia and related myeloid malignancies. Am J Hematol. 2018;93(3):401-7.

13. DiNardo CD, Pratz K, Pullarkat V, Jonas BA, Arellano M, Becker PS, et al. Venetoclax combined with decitabine or azacitidine in treatment-naive, elderly patients with acute myeloid leukemia. Blood. 2019;133(1):7-17.

14. Wei AH, Strickland SA, Jr., Hou JZ, Fiedler W, Lin TL, Walter RB, et al. Venetoclax Combined With LowDose Cytarabine for Previously Untreated Patients With Acute Myeloid Leukemia: Results From a Phase Ib/II Study. J Clin Oncol. 2019;37(15):1277-84.

15. DiNardo CD, Jonas BA, Pullarkat V, Thirman MJ, Garcia JS, Wei AH, et al. Azacitidine and Venetoclax in Previously Untreated Acute Myeloid Leukemia. N Engl J Med. 2020;383(7):617-29.

16. Cang S, Iragavarapu C, Savooji J, Song Y, Liu D. ABT-199 (venetoclax) and BCL-2 inhibitors in clinical development. J Hematol Oncol. 2015;8:129.

17. Lai C, Doucette K, Norsworthy K. Recent drug approvals for acute myeloid leukemia. J Hematol Oncol. 2019;12(1):100.

18. Glaser SP, Lee EF, Trounson E, Bouillet P, Wei A, Fairlie WD, et al. Anti-apoptotic Mcl-1 is essential for the development and sustained growth of acute myeloid leukemia. Genes Dev. 2012;26(2):120-5.

19. Yoshimoto G, Miyamoto T, Jabbarzadeh-Tabrizi S, lino T, Rocnik JL, Kikushige Y, et al. FLT3-ITD upregulates MCL-1 to promote survival of stem cells in acute myeloid leukemia via FLT3-ITD-specific STAT5 activation. Blood. 2009;114(24):5034-43.

20. Wei AH, Roberts AW, Spencer A, Rosenberg AS, Siegel D, Walter RB, et al. Targeting MCL-1 in hematologic malignancies: Rationale and progress. Blood Rev. 2020:100672.

21. Pan R, Ruvolo VR, Wei J, Konopleva M, Reed JC, Pellecchia M, et al. Inhibition of Mcl-1 with the panBcl-2 family inhibitor (-)BI97D6 overcomes ABT-737 resistance in acute myeloid leukemia. Blood. 2015;126(3):363-72. 
22. Yamaguchi R, Lartigue L, Perkins G. Targeting Mcl-1 and other $\mathrm{Bcl}-2$ family member proteins in cancer therapy. Pharmacol Ther. 2019;195:13-20.

23. Hird AW, Tron AE. Recent advances in the development of Mcl-1 inhibitors for cancer therapy. Pharmacol Ther. 2019;198:59-67.

24. Lengfelder E, Hofmann WK, Nowak D. Impact of arsenic trioxide in the treatment of acute promyelocytic leukemia. Leukemia. 2012;26(3):433-42.

25. Coombs CC, Tavakkoli M, Tallman MS. Acute promyelocytic leukemia: where did we start, where are we now, and the future. Blood Cancer J. 2015;5:e304.

26. Ades L, Thomas X, Bresler AG, Raffoux E, Spertini O, Vey N, et al. Arsenic trioxide is required in the treatment of newly diagnosed acute promyelocytic leukemia. Analysis of a randomized trial (APL 2006) by the French Belgian Swiss APL group. Haematologica. 2018;103(12):2033-9.

27. Miller WH, Jr., Schipper HM, Lee JS, Singer J, Waxman S. Mechanisms of action of arsenic trioxide. Cancer Res. 2002;62(14):3893-903.

28. Kumar S, Yedjou CG, Tchounwou PB. Arsenic trioxide induces oxidative stress, DNA damage, and mitochondrial pathway of apoptosis in human leukemia (HL-60) cells. J Exp Clin Cancer Res. 2014;33:42.

29. Wang R, Xia L, Gabrilove J, Waxman S, Jing Y. Downregulation of Mcl-1 through GSK-3beta activation contributes to arsenic trioxide-induced apoptosis in acute myeloid leukemia cells. Leukemia. 2013;27(2):315-24.

30. Yang IH, Hong SH, Jung M, Ahn CH, Yoon HJ, Hong SD, et al. Cryptotanshinone chemosensitivity potentiation by TW-37 in human oral cancer cell lines by targeting STAT3-Mcl-1 signaling. Cancer Cell Int. 2020;20:405.

31. Ramsey HE, Fischer MA, Lee T, Gorska AE, Arrate MP, Fuller L, et al. A Novel MCL1 Inhibitor Combined with Venetoclax Rescues Venetoclax-Resistant Acute Myelogenous Leukemia. Cancer Discov. 2018;8(12):1566-81.

32. Cheong JW, Jung HI, Eom JI, Kim SJ, Jeung HK, Min YH. Aurora-A kinase inhibition enhances the cytosine arabinoside-induced cell death in leukemia cells through apoptosis and mitotic catastrophe. Cancer Lett. 2010;297(2):171-81.

33. Nakajima W, Hicks MA, Tanaka N, Krystal GW, Harada H. Noxa determines localization and stability of MCL-1 and consequently ABT-737 sensitivity in small cell lung cancer. Cell Death Dis. 2014;5:e1052.

34. Konopleva M, Milella M, Ruvolo P, Watts JC, Ricciardi MR, Korchin B, et al. MEK inhibition enhances ABT-737-induced leukemia cell apoptosis via prevention of ERK-activated MCL-1 induction and modulation of MCL-1/BIM complex. Leukemia. 2012;26(4):778-87.

35. Han L, Zhang Q, Dail M, Shi C, Cavazos A, Ruvolo VR, et al. Concomitant targeting of BCL2 with venetoclax and MAPK signaling with cobimetinib in acute myeloid leukemia models. Haematologica. 2020;105(3):697-707. 
36. Gores GJ, Kaufmann SH. Selectively targeting Mcl-1 for the treatment of acute myelogenous leukemia and solid tumors. Genes Dev. 2012;26(4):305-11.

37. Teh TC, Nguyen NY, Moujalled DM, Segal D, Pomilio G, Rijal S, et al. Enhancing venetoclax activity in acute myeloid leukemia by co-targeting MCL1. Leukemia. 2018;32(2):303-12.

38. Moujalled DM, Pomilio G, Ghiurau C, Ivey A, Salmon J, Rijal S, et al. Combining BH3-mimetics to target both BCL-2 and MCL1 has potent activity in pre-clinical models of acute myeloid leukemia. Leukemia. 2019;33(4):905-17.

39. Prukova D, Andera L, Nahacka Z, Karolova J, Svaton M, Klanova M, et al. Cotargeting of BCL2 with Venetoclax and MCL1 with S63845 Is Synthetically Lethal In Vivo in Relapsed Mantle Cell Lymphoma. Clin Cancer Res. 2019;25(14):4455-65.

40. Caenepeel S, Brown SP, Belmontes B, Moody G, Keegan KS, Chui D, et al. AMG 176, a Selective MCL1 Inhibitor, Is Effective in Hematologic Cancer Models Alone and in Combination with Established Therapies. Cancer Discov. 2018;8(12):1582-97.

41. Wang X, Bathina M, Lynch J, Koss B, Calabrese C, Frase S, et al. Deletion of MCL-1 causes lethal cardiac failure and mitochondrial dysfunction. Genes Dev. 2013;27(12):1351-64.

42. Vick B, Weber A, Urbanik T, Maass T, Teufel A, Krammer PH, et al. Knockout of myeloid cell leukemia1 induces liver damage and increases apoptosis susceptibility of murine hepatocytes. Hepatology. 2009;49(2):627-36.

43. Rasmussen ML, Kline LA, Park KP, Ortolano NA, Romero-Morales Al, Anthony CC, et al. A Nonapoptotic Function of MCL-1 in Promoting Pluripotency and Modulating Mitochondrial Dynamics in Stem Cells. Stem Cell Reports. 2018;10(3):684-92.

44. Fogarty LC, Flemmer RT, Geizer BA, Licursi M, Karunanithy A, Opferman JT, et al. Mcl-1 and Bcl-xL are essential for survival of the developing nervous system. Cell Death Differ. 2019;26(8):1501-15.

45. Luedtke DA, Su Y, Liu S, Edwards H, Wang Y, Lin H, et al. Inhibition of XPO1 enhances cell death induced by ABT-199 in acute myeloid leukaemia via Mcl-1. J Cell Mol Med. 2018;22(12):6099-111.

46. Zhu ZC, Liu JW, Yang C, Zhao M, Xiong ZQ. XP01 inhibitor KPT-330 synergizes with Bcl-xL inhibitor to induce cancer cell apoptosis by perturbing rRNA processing and $\mathrm{Mcl}-1$ protein synthesis. Cell Death Dis. 2019;10(6):395.

47. Zhang S, Zhang M, Jing Y, Yin X, Ma P, Zhang Z, et al. Deubiquitinase USP13 dictates MCL1 stability and sensitivity to BH3 mimetic inhibitors. Nat Commun. 2018;9(1):215.

48. Wang R, Xia L, Gabrilove J, Waxman S, Jing Y. Sorafenib Inhibition of Mcl-1 Accelerates ATRAInduced Apoptosis in Differentiation-Responsive AML Cells. Clin Cancer Res. 2016;22(5):1211-21.

49. Arai S, Jonas O, Whitman MA, Corey E, Balk SP, Chen S. Tyrosine Kinase Inhibitors Increase MCL1 Degradation and in Combination with BCLXL/BCL2 Inhibitors Drive Prostate Cancer Apoptosis. Clin Cancer Res. 2018;24(21):5458-70.

50. Premkumar DR, Jane EP, Foster KA, Pollack IF. Survivin inhibitor YM-155 sensitizes tumor necrosis factor- related apoptosis-inducing ligand-resistant glioma cells to apoptosis through $\mathrm{Mcl}-1$ 
downregulation and by engaging the mitochondrial death pathway. J Pharmacol Exp Ther. 2013;346(2):201-10.

51. Cidado J, Boiko S, Proia T, Ferguson D, Criscione SW, San Martin M, et al. AZD4573 Is a Highly Selective CDK9 Inhibitor That Suppresses MCL-1 and Induces Apoptosis in Hematologic Cancer Cells. Clin Cancer Res. 2020;26(4):922-34.

52. Boffo S, Damato A, Alfano L, Giordano A. CDK9 inhibitors in acute myeloid leukemia. J Exp Clin Cancer Res. 2018;37(1):36.

53. Pan R, Ruvolo V, Mu H, Leverson JD, Nichols G, Reed JC, et al. Synthetic Lethality of Combined Bcl-2 Inhibition and p53 Activation in AML: Mechanisms and Superior Antileukemic Efficacy. Cancer Cell. 2017;32(6):748-60 e6.

54. Knorr KL, Schneider PA, Meng XW, Dai H, Smith BD, Hess AD, et al. MLN4924 induces Noxa upregulation in acute myelogenous leukemia and synergizes with Bcl-2 inhibitors. Cell Death Differ. 2015;22(12):2133-42.

55. Tambe M, Karjalainen E, Vaha-Koskela M, Bulanova D, Gjertsen BT, Kontro M, et al. Pan-RAF inhibition induces apoptosis in acute myeloid leukemia cells and synergizes with BCL2 inhibition. Leukemia. 2020.

56. Lehmann C, Friess T, Birzele F, Kiialainen A, Dangl M. Superior anti-tumor activity of the MDM2 antagonist idasanutlin and the Bcl-2 inhibitor venetoclax in p53 wild-type acute myeloid leukemia models. J Hematol Oncol. 2016;9(1):50.

57. Jacque N, Ronchetti AM, Larrue C, Meunier G, Birsen R, Willems L, et al. Targeting glutaminolysis has antileukemic activity in acute myeloid leukemia and synergizes with BCL-2 inhibition. Blood. 2015;126(11):1346-56.

58. Wang QQ, Jiang $Y$, Naranmandura $H$. Therapeutic strategy of arsenic trioxide in the fight against cancers and other diseases. Metallomics. 2020;12(3):326-36.

59. Zhu HH, Qian JJ, Sun WJ, You LS, Wang QQ, Naranmandura H, et al. Venetoclax and arsenic showed synergistic anti-leukemia activity in vitro and in vivo for acute myeloid leukemia with the NPM1 mutation. Am J Hematol. 2020;95(3):E55-E7.

60. Martelli MP, Gionfriddo I, Mezzasoma F, Milano F, Pierangeli S, Mulas F, et al. Arsenic trioxide and alltrans retinoic acid target NPM1 mutant oncoprotein levels and induce apoptosis in NPM1-mutated AML cells. Blood. 2015;125(22):3455-65.

61. Li X, Zeng $X, X u Y$, Wang $B$, Zhao $Y$, Lai $X$, et al. Mechanisms and rejuvenation strategies for aged hematopoietic stem cells. J Hematol Oncol. 2020;13(1):31.

62. Essers MA, Trumpp A. Targeting leukemic stem cells by breaking their dormancy. Mol Oncol. 2010;4(5):443-50.

63. Parmar S, Rundhaugen LM, Boehlke L, Riley M, Nabhan C, Raji A, et al. Phase Il trial of arsenic trioxide in relapsed and refractory acute myeloid leukemia, secondary leukemia and/or newly diagnosed patients at least 65 years old. Leuk Res. 2004;28(9):909-19. 
64. Wang R, Li Y, Gong P, Gabrilove J, Waxman S, Jing Y. Arsenic Trioxide and Sorafenib Induce Synthetic Lethality of FLT3-ITD Acute Myeloid Leukemia Cells. Mol Cancer Ther. 2018;17(9):1871-80.

65. Au WY, Kwong YL. Arsenic trioxide: safety issues and their management. Acta Pharmacol Sin. 2008;29(3):296-304.

66. DiNardo CD, Wei AH. How I treat acute myeloid leukemia in the era of new drugs. Blood. 2020;135(2):85-96.

67. Touzeau C, Dousset C, Le Gouill S, Sampath D, Leverson JD, Souers AJ, et al. The Bcl-2 specific BH3 mimetic ABT-199: a promising targeted therapy for $\mathrm{t}(11 ; 14)$ multiple myeloma. Leukemia. 2014;28(1):210-2.

\section{Figures}


Figure 1

a

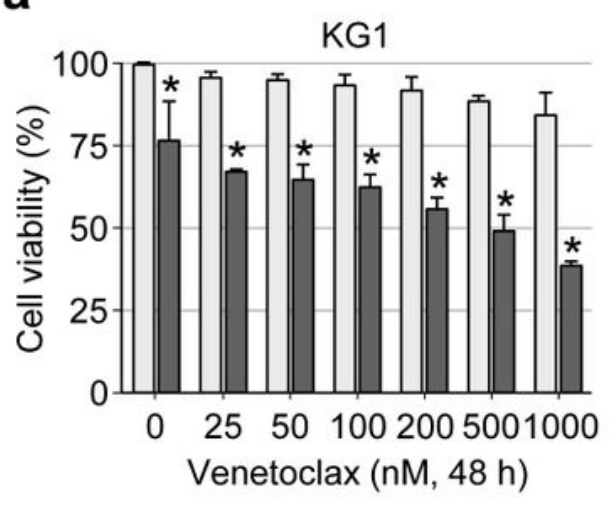

C

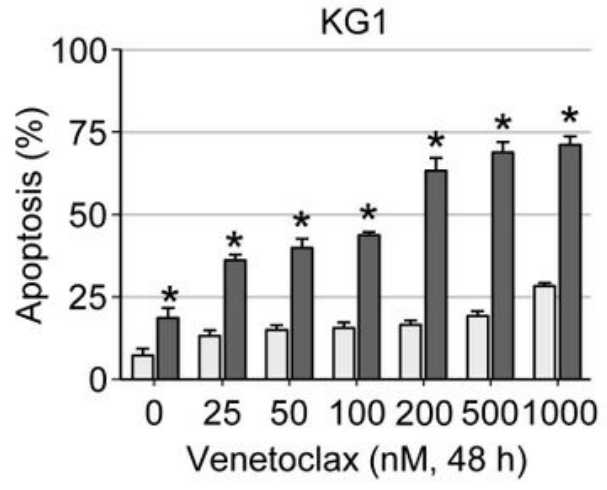

e

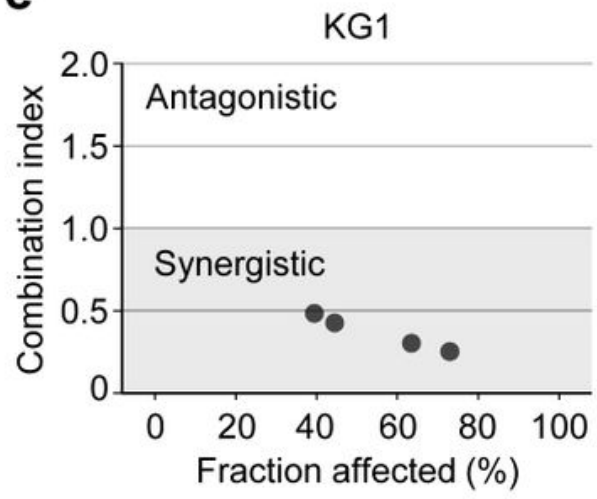

b
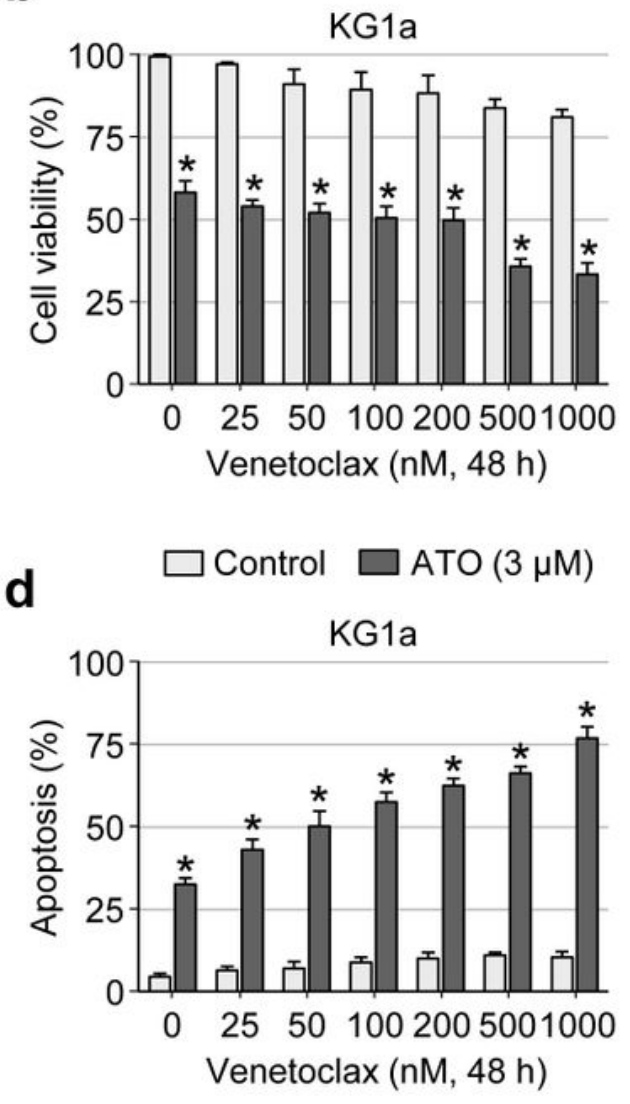

f

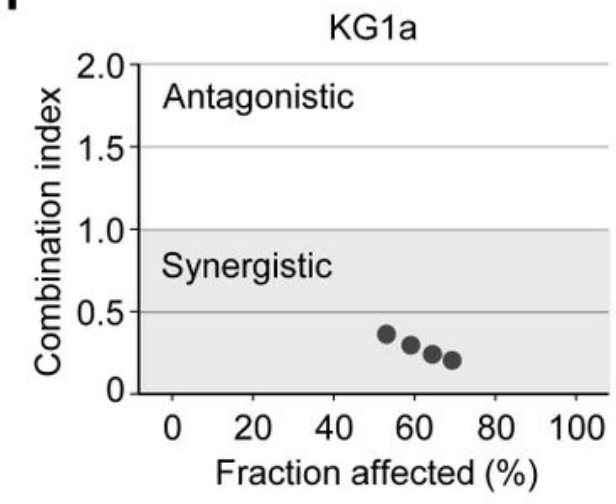

\section{Figure 1}

Venetoclaxdose-dependently impairs cell viability and synergistically promotes apoptosis in KG1 and KG1a cells when in combination with ATO. a ,b, Assessment of cell viability in KG1 (a) and KG1a (b) cells treated with the indicated concentration of venetoclax $(0-1,000 \mathrm{nM})$ with or without ATO $(3 \mu \mathrm{M})$ for $48 \mathrm{~h}$. Cell viability was assessed by measuring the absorbance at $450 \mathrm{~nm}$ after incubating the treated cells for $4 \mathrm{~h}$ with Cell Counting Kit-8 solution (Dojindo). Values were obtained from three independent experiments, 
and horizontal bars indicate mean \pm s.d. ${ }^{*} \mathrm{P}<0.05$ versus respective control by two-tailed Mann-Whitney Utest. c, d, Summary data of the percentage of apoptotic fraction in KG1 (c) and KG1a (d) cells, as assessed by AnnexinV and PI staining and flow cytometricanalysis after treatment with the indicated concentration of venetoclax $(0-1,000 \mathrm{nM})$ with or without ATO $(3 \mu \mathrm{M})$ for $48 \mathrm{~h}$. Values were obtained from three independent experiments, and horizontal bars indicate mean \pm s.d. ${ }^{*} P<0.05$ versus control treatment by two-tailed Mann-WhitneyUtest. e, $\mathrm{f}$, Combination index of apoptotic cells after treatment with venetoclaxand ATO in KG1 (e) and KG1a (f) cells. Values were obtained by median dose-effect analysis, and each dot indicates the value obtained from six independent experiments.

Figure 2

a
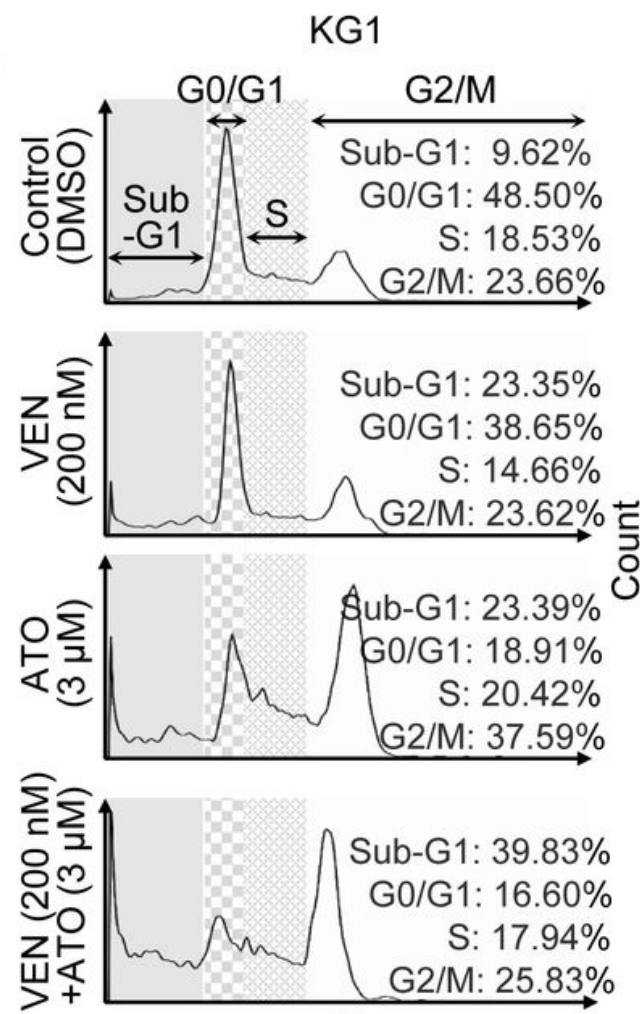

PI
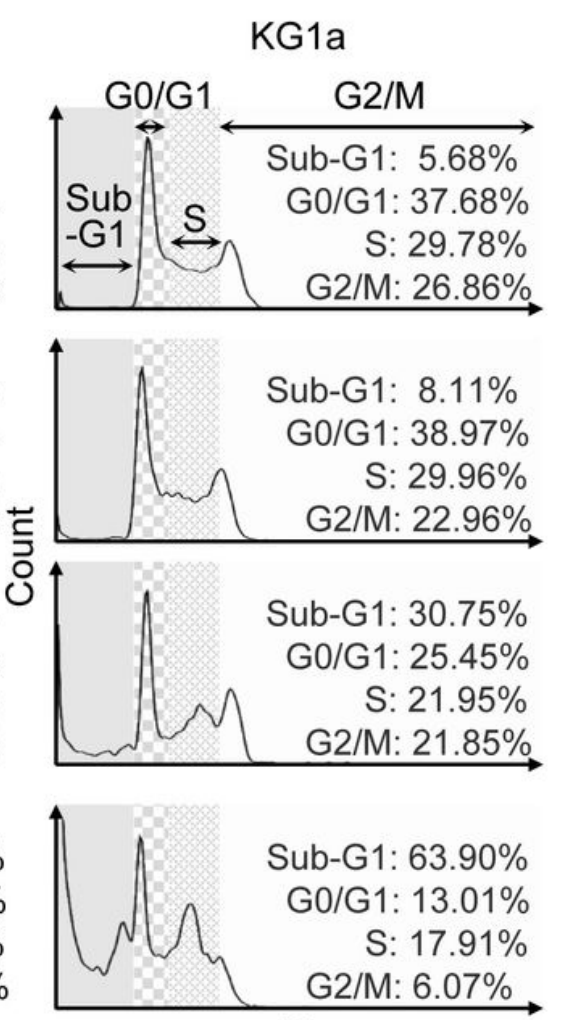

$\mathrm{PI}$ b
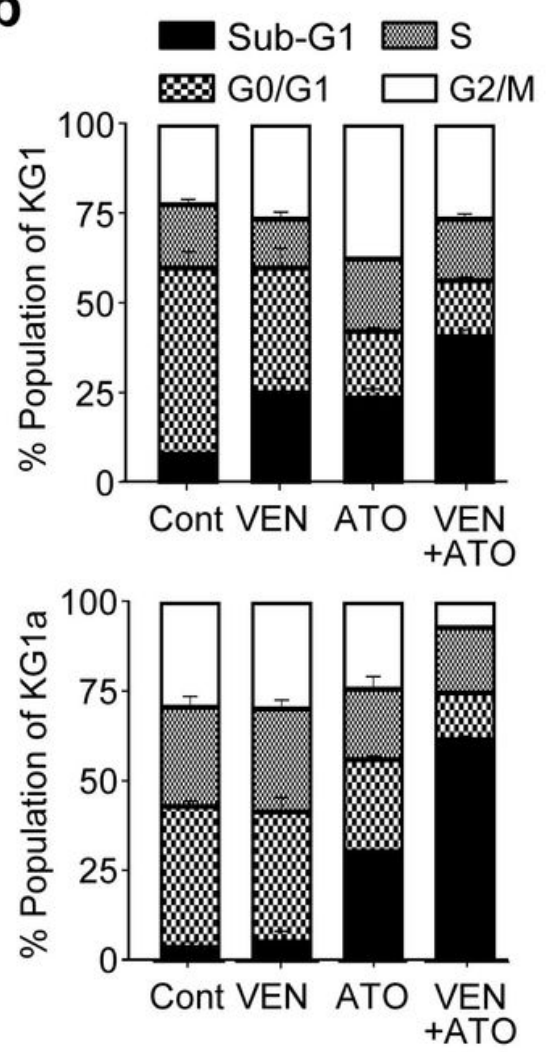

\section{Figure 2}

The combination of venetoclaxand ATO disrupts the KG1 and KG1a cell cycles. a, b, Cell-cycle analysis by flow cytometry after treatment with control (DMSO $0.1 \% \mathrm{v} / \mathrm{v})$, venetoclax $(200 \mathrm{nM})$, ATO $(3 \mu \mathrm{M})$, or the combination of venetoclax $(200 \mathrm{nM})$ and ATO $(3 \mu \mathrm{M})$ for $48 \mathrm{~h}$. Representative histograms of the cell cycles of the gated live KG1 and KG1a cells after treatment (a) and their summary data (b). Values were obtained from three independent experiments, and horizontal bars indicate mean \pm s.d. 
Figure 3

a

BMMCs from AML patients ( $n=4$ patients)
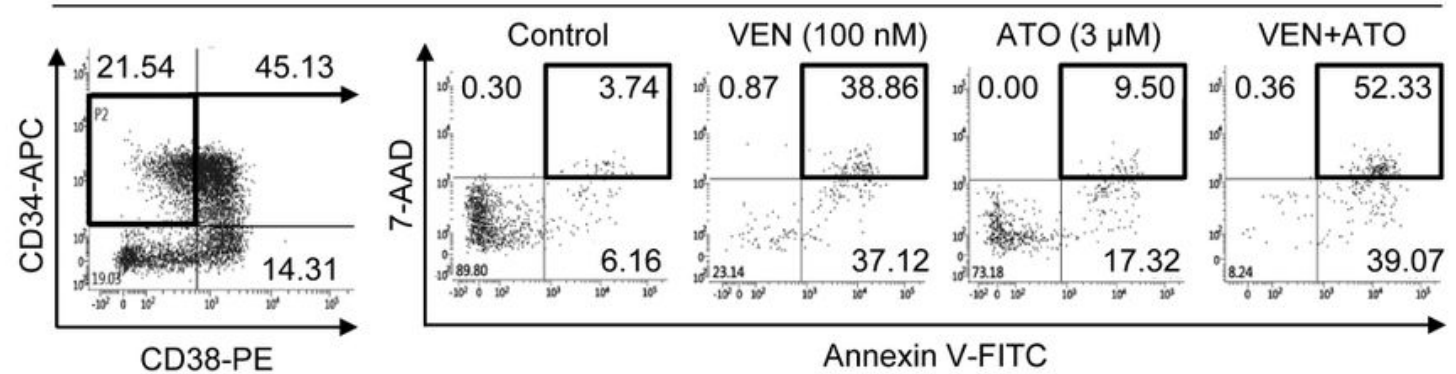

b
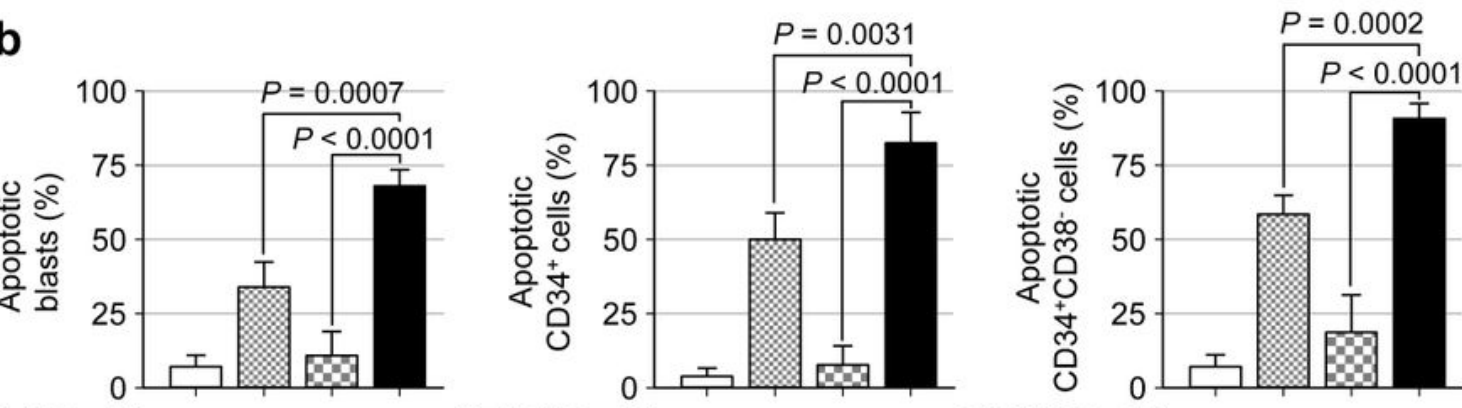

$\operatorname{VEN}(100 \mathrm{nM})-+-+\operatorname{VEN}(100 \mathrm{nM})-+-+\operatorname{VEN}(100 \mathrm{nM})-+$ ATO $(3 \mu \mathrm{M})--++$ ATO $(3 \mu \mathrm{M})--++$ ATO $(3 \mu \mathrm{M})-+$

C BMMCs from healthy donors ( $n=4$ donors)

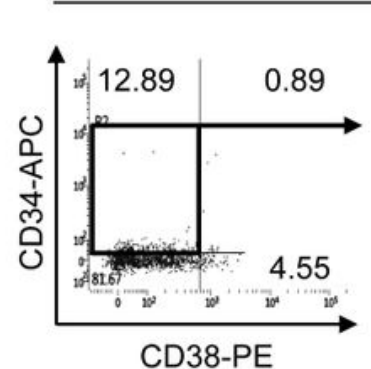

d

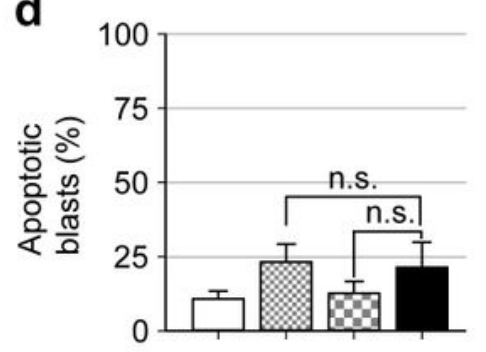

$\operatorname{VEN}(100 \mathrm{nM})-+++$

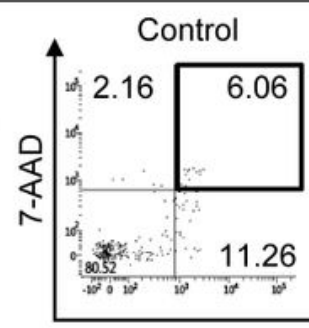

VEN $(100 \mathrm{nM})$

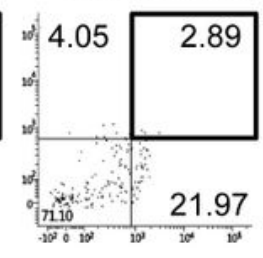

Annexin V-FITC
ATO $(3 \mu \mathrm{M}) \quad$ VEN+ATO
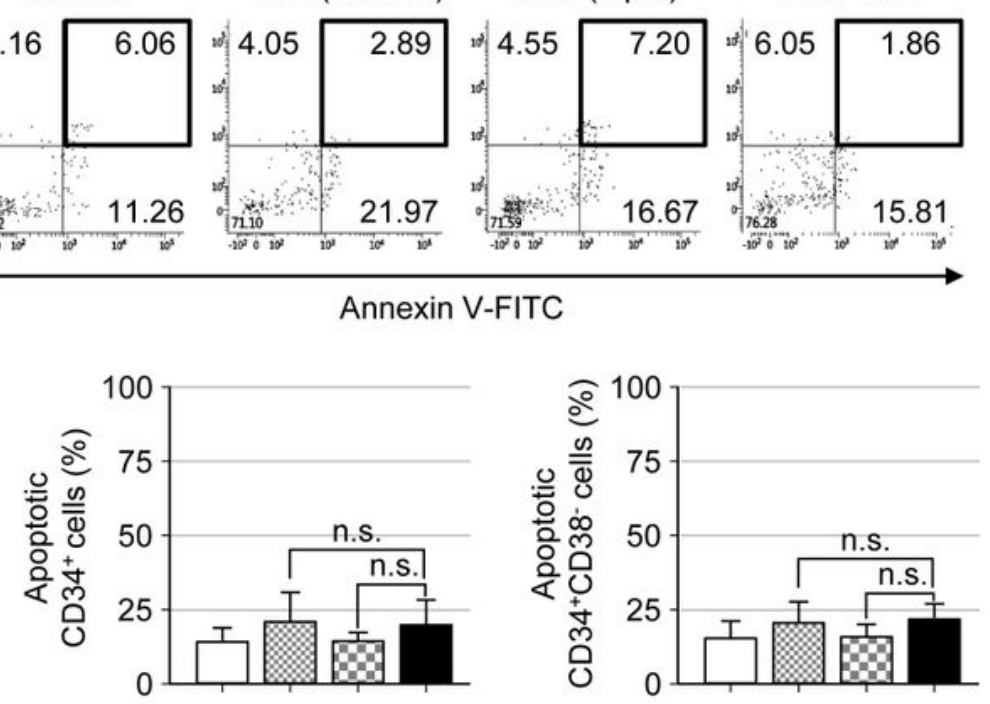

$\operatorname{VEN}(100 \mathrm{nM})-+-+\operatorname{VEN}(100 \mathrm{nM})-+-+$ ATO $(3 \mu \mathrm{M})--++$ ATO $(3 \mu \mathrm{M})--++$

\section{Figure 3}

The venetoclaxand ATO combination preferentially induces apoptosis of primary LSCs from AML patients while sparing healthy donor HSCs. a, b, Representative flow cytometricanalysis (a) and summary data (b) of the percentage of AnnexinV+7-AAD+apoptotic cells after gating for CD34+CD38-primary $A M L$ cells in the BMMCs of AML patients at diagnosis after treatment with venetoclax(100 nM), ATO (3 $\mu M)$, or both in combination for $48 \mathrm{~h}$ in total mononuclear cells (b, far left), gated CD34+cells (b, middle), or 
CD34+CD38-cells ( $b$, far right). Values were obtained from two independent experiments of $n=4$ patients, and horizontal bars indicate mean \pm s.d. ${ }^{*} \mathrm{P}$ values versus control treatment by two-tailed Mann-Whitney Utest. n.s., not significant. c, d, Representative flow cytometricanalysis (c) and summary data (d) of the percentage of AnnexinV+7-AAD+apoptotic cells after gating for CD34+CD38-cells in the BMMCs of healthy donors following treatment with venetoclax $(100 \mathrm{nM})$, ATO $(3 \mu \mathrm{M})$, or both in combination for $48 \mathrm{~h}$ in total mononuclear cells (d, far left), gated CD34+cells (d, middle), or CD34+CD38-cells (d, far right). Values were obtained from two independent experiments of $n=4$ healthy donors, and horizontal bars indicate mean \pm s.d. ${ }^{*}$ Pvalues versus control treatment by two-tailed Mann-Whitney Utest. n.s., not significant.

Figure 4
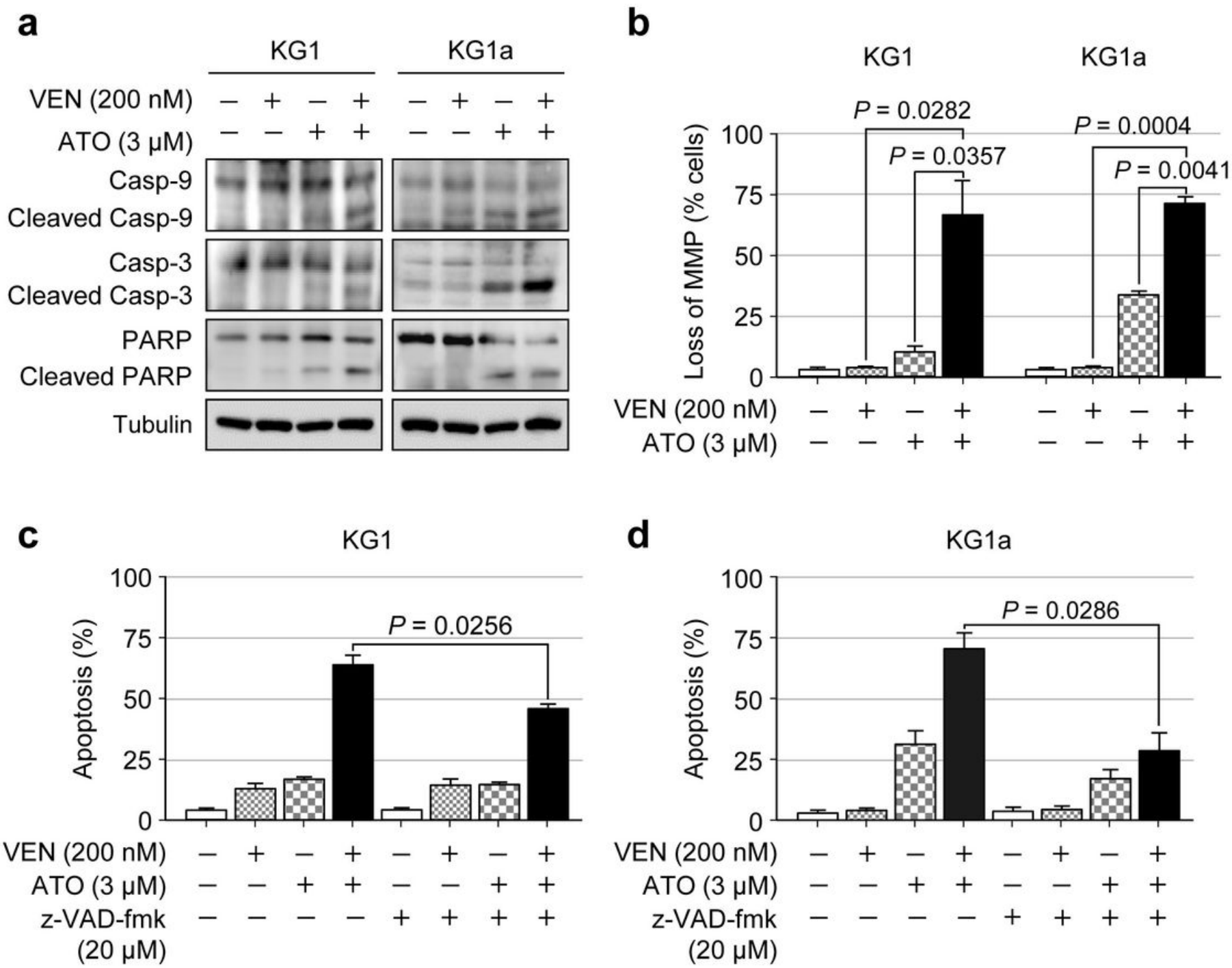

\section{Figure 4}

The combination of venetoclaxand ATO promotes caspase-dependent apoptosis in KG1 and KG1a cells. a, Representative western blot analysis of the indicated proteins in KG1 and KG1a cells treated with 
venetoclax $(200 \mathrm{nM})$, ATO $(3 \mu \mathrm{M})$, or both in combination for $48 \mathrm{~h}$. Similar results were obtained from three independent experiments. b, Summary data of MMP disruption, as assessed by flow cytometry, using the DePsipherKit (Trevigen) in KG1 and KG1a cells treated with venetoclax(200 nM), ATO $(3 \mu \mathrm{M})$, or both in combination for $48 \mathrm{~h}$. Values were obtained from three independent experiments, and horizontal bars indicate mean \pm s.d. ${ }^{*}$ Pvalues versus control treatment by two-tailed Mann-Whitney Utest. n.s., not significant. c, d, Summary data of the percentage of apoptotic cells, as assessed by AnnexinV/PI staining and flow cytometricanalysis after treatment with or without the pan-caspase inhibitor z-VAD-fmk(20 $\mu \mathrm{M})$ for $2 \mathrm{~h}$ prior to the addition of venetoclax $(200 \mathrm{nM})$, ATO $(3 \mu \mathrm{M})$, or both in combination for $48 \mathrm{~h}$ in KG1 (c) and KG1a (d) cells. Values were obtained from three independent experiments, and horizontal bars indicate mean \pm s.d. ${ }^{*}$ Pvalues versus control treatment with or without z-VAD-fmkby two-tailed MannWhitney Utest. n.s., not significant. 
Figure 5

a

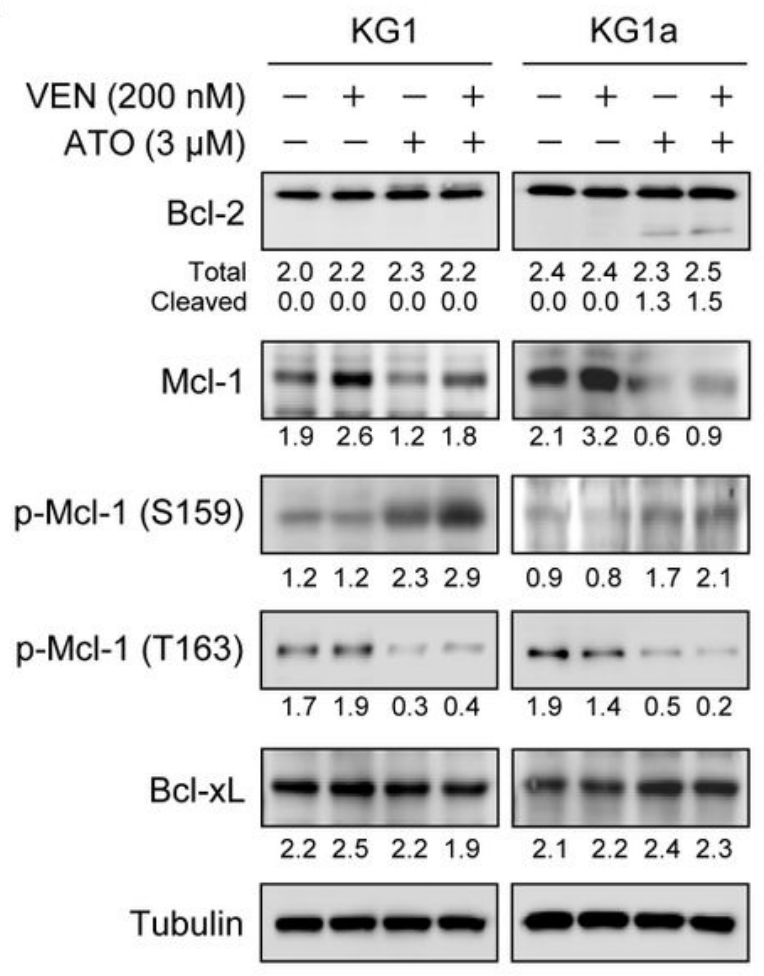

b
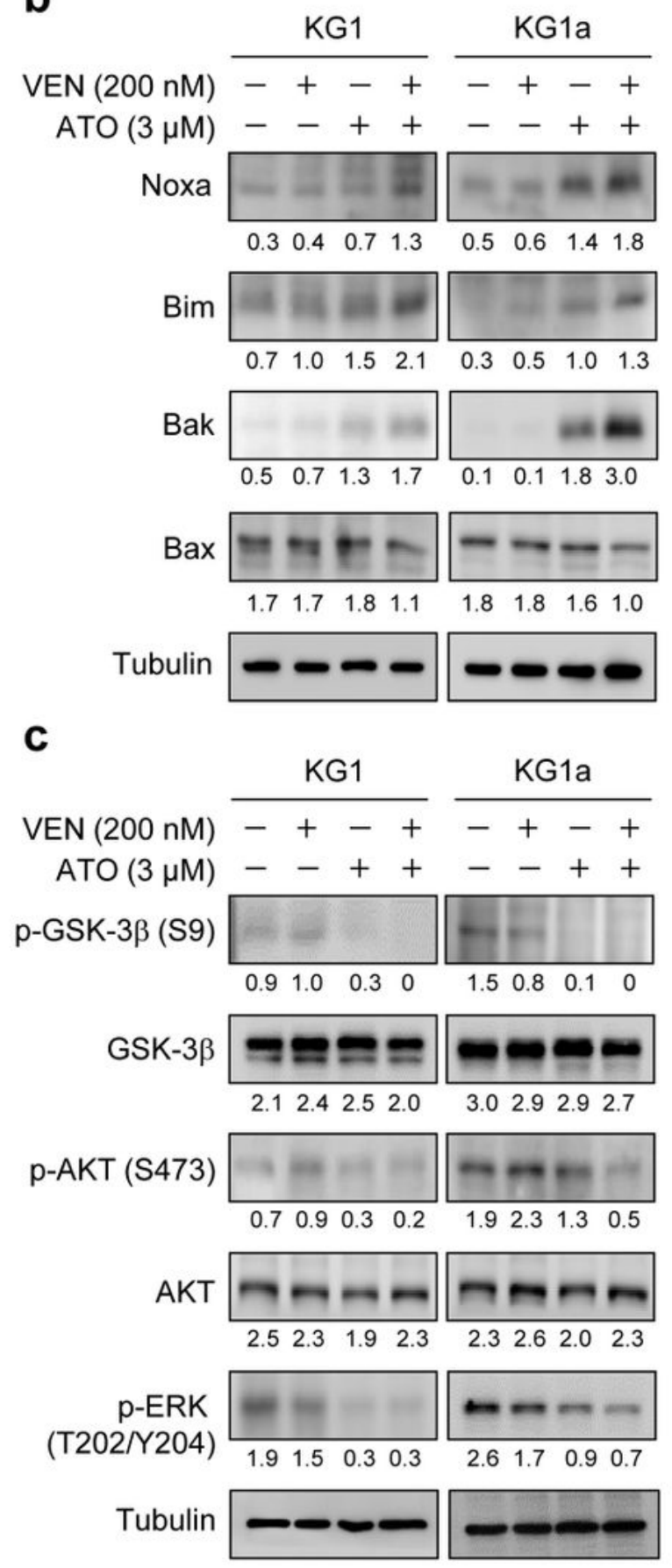

\section{Figure 5}

The venetoclaxand ATO combination downregulates Mcl-1 through GSK-3 $\beta$ activation in KG1 and KG1a cells. a-c, Representative western blot analysis of the indicated proteins in KG1 and KG1a cells treated with venetoclax $(200 \mathrm{nM})$, ATO $(3 \mu \mathrm{M})$, or both in combination for $48 \mathrm{~h}$. Similar results were obtained from three independent experiments. 
a

Figure 6

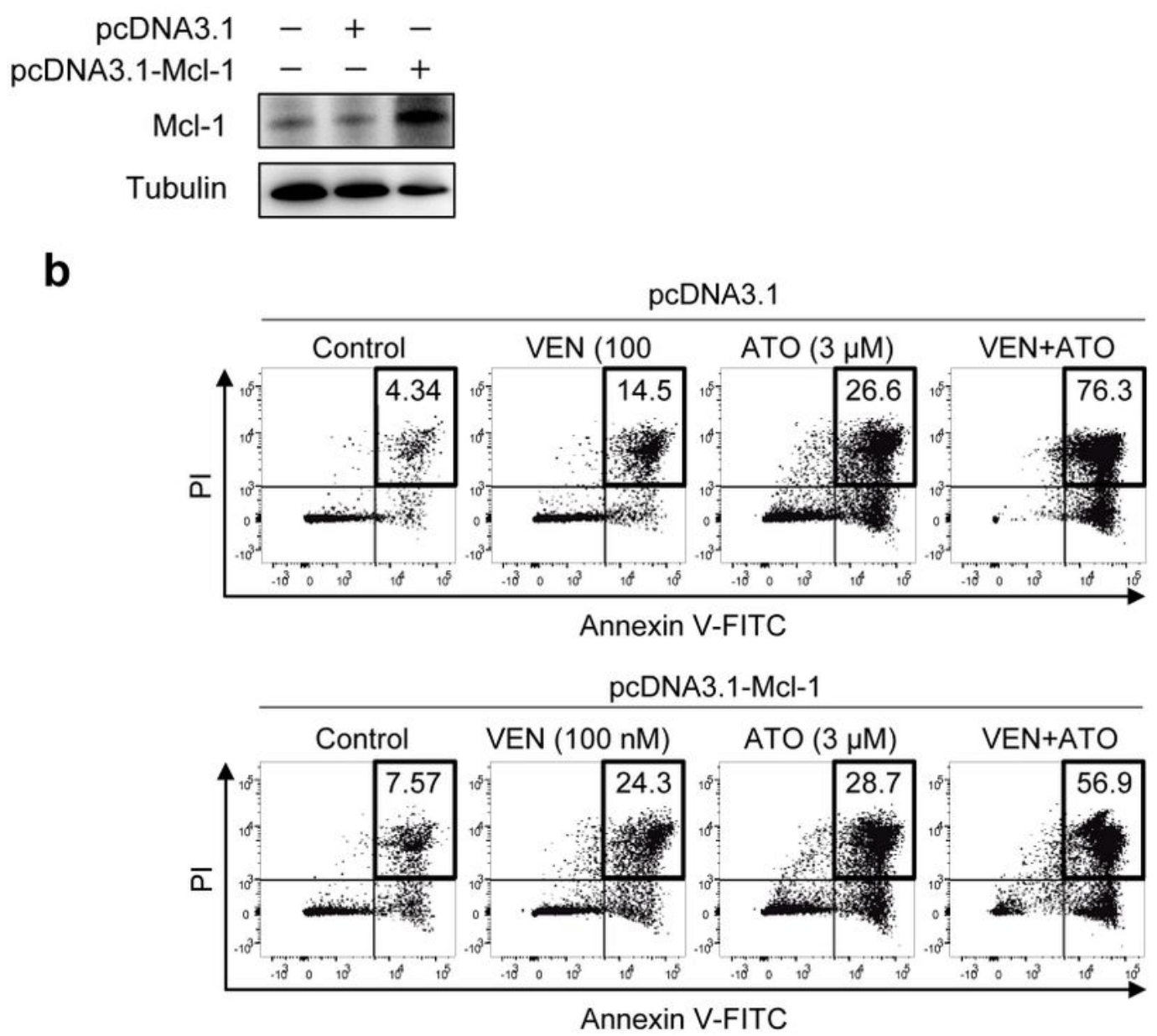

C

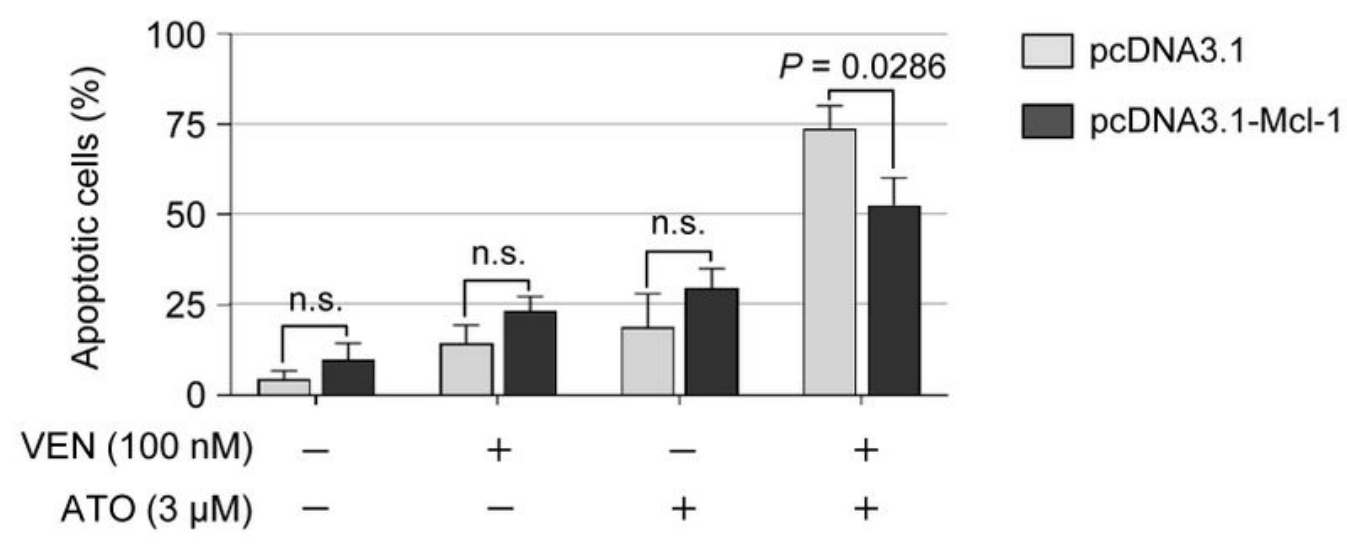

Figure 6

Mcl-1 overexpression alleviates apoptosis induced by the combination of venetoclaxand ATO in KG1a cells. a, Western blot analysis of indicated proteins in KG1a cells treated with venetoclax(200 nM), ATO (3 $\mu \mathrm{M})$, or both in combination for $48 \mathrm{~h}$ after transfection with pcDNA3.1 control or pcDNA3.1-Mcl-1 vector. b, c, Representative flow cytometricanalysis (b) and summary data (c) of the percentage of AnnexinV+PI+apoptotic cells in KG1a cells transfected with pcDNA3.1 control or pcDNA3.1-Mcl-1 vector 
after treatment with venetoclax $(100 \mathrm{nM})$, ATO $(3 \mu \mathrm{M})$, or both in combination for $48 \mathrm{~h}$. Values were obtained from two independent experiments, and horizontal bars indicate mean \pm s.d. ${ }^{*} \mathrm{P}$ valuesversus control treatment by two-tailed Mann-Whitney Utest. n.s., not significant.

Figure 7

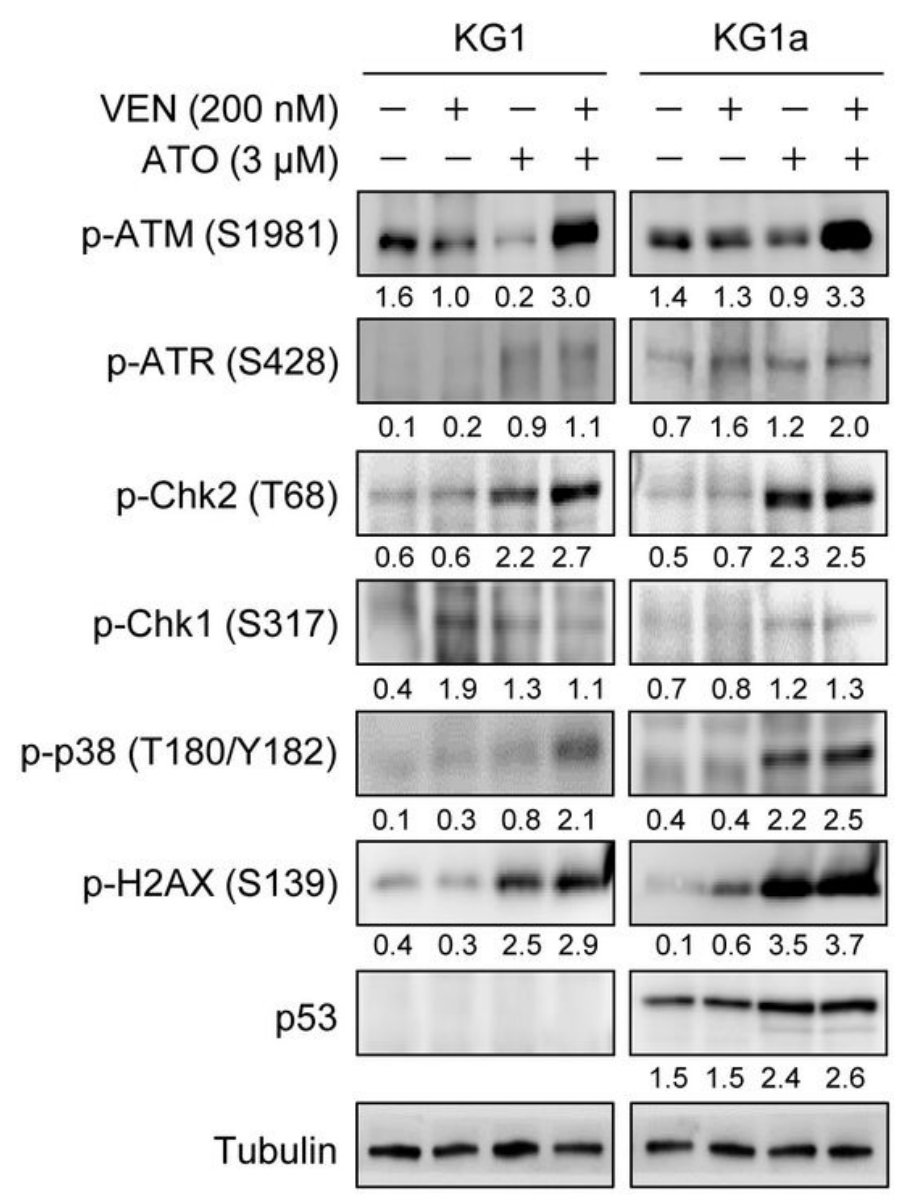

Figure 7

The venetoclaxand ATO combination triggers robust DNA damage response. Representative western blot analysis of the indicated proteins in KG1 and KG1a cells treated with venetoclax(200 nM), ATO ( $3 \mu \mathrm{M})$, or both in combination for $48 \mathrm{~h}$. Similar results were obtained from three independent experiments. 


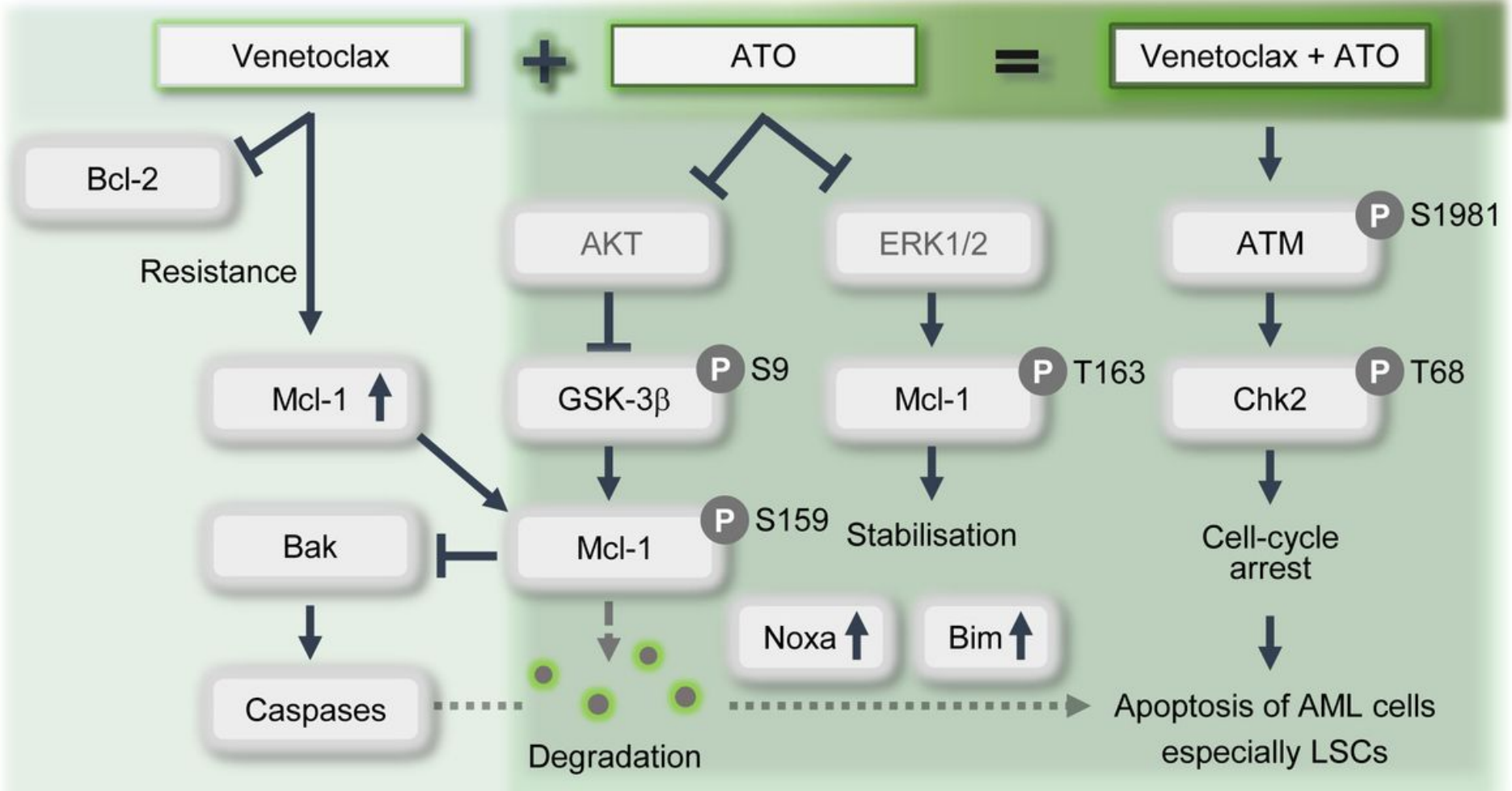

\section{Figure 8}

Proposed mechanism of synergistic action between venetoclax and ATO. Schematic diagram depicting the synergism between venetoclax and ATO in LSC-like leukaemia cells and primary LSCs. Bcl-2 inhibition by venetoclax in LSC-like leukaemia cells leads to the upregulation of Mcl-1, which confers resistance to venetoclax. However, upon combination treatment with venetoclax and ATO, AKT is attenuated and

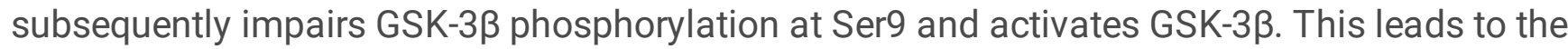
phosphorylation of Mcl-1 at Ser159, triggering Mcl-1 degradation. The levels of Noxa and Bim, which are normally sequestered by $\mathrm{Mcl}-1$, are elevated upon Mcl-1 degradation and promote caspase-dependent apoptosis associated with Bak activation. In parallel, ERK downregulation attenuates $\mathrm{Mcl}-1$ phosphorylation at Thr163, leading to Mcl-1 destabilisation. The venetoclax and ATO combination also induces the phosphorylation of ATM at Ser1981 and Chk2 at Thr68, promoting cell cycle arrest associated with a robust DNA damage response and apoptosis.

\section{Supplementary Files}

This is a list of supplementary files associated with this preprint. Click to download.

- VENandATOinAMLSupplementaryTable1.docx 